Article

\title{
Head Losses of Horizontal Bar Racks as Fish Guidance Structures
}

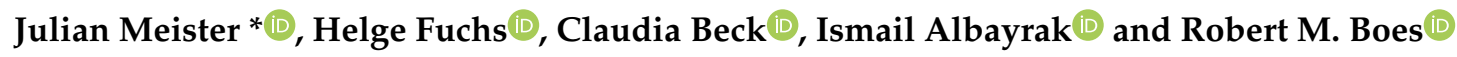 \\ Laboratory of Hydraulics, Hydrology and Glaciology (VAW), ETH Zurich, 8093 Zurich, Switzerland; \\ fuchs@vaw.baug.ethz.ch (H.F.); beck@vaw.baug.ethz.ch (C.B.); albayrak@vaw.baug.ethz.ch (I.A.); \\ boes@vaw.baug.ethz.ch (R.M.B.) \\ * Correspondence: meister@vaw.baug.ethz.ch
}

Received: 26 November 2019; Accepted: 1 February 2020; Published: 11 February 2020

\begin{abstract}
Horizontal bar racks have been used as trash racks at hydropower plants since the 1920s. With the installation of the first horizontal bar rack bypass system at a hydropower plant as a downstream fish passage facility in 2006, these racks rapidly gained importance as fish protection measures. Since then, they have been installed at more than 100 small- to medium-sized hydropower plants in Europe. Despite the large number of installed racks, systematic investigations of the head losses and velocity fields were missing. On the basis of detailed hydraulic experimentation with a large number of rack parameters and including up-to-date foil-shaped bars, the layout of horizontal bar racks and their hydraulic performance were assessed in the current study. This paper reports the results of the rack head loss investigation, whereas the accompanying paper entitled Velocity Fields at Horizontal Bar Racks as Fish Guidance Structures focuses on the up- and downstream velocity fields. By applying foil-shaped bars instead of rectangular bars, the loss coefficient was reduced by more than $40 \%$, depending on the rack configuration. Bottom and top overlays are used to increase the guidance efficiency for fish, sediments, and floating debris. However, the altered flow field results in increased head losses. A new set of equations is proposed to predict head losses for current horizontal bar racks, including overlays for various hydropower plant layouts. The predictions are compared to literature data.
\end{abstract}

Keywords: downstream fish migration; fish control structures; fish guidance structure; fish passages; fish protection; head loss; horizontal bar rack; laboratory studies

\section{Introduction}

The natural behavior of many fish species involves the migration of up to hundreds of kilometers within river systems. After man-made river engineering modifications have been intensely implemented over the last two centuries, the ecological river continuums are interrupted by numerous transverse structures such as sills, weirs, and hydropower plants (HPPs). Following the implementation of the European Water Framework Directive and the revised Swiss Waters Protection Act, fish downstream migration has rapidly gained importance in recent years. More than a hundred small- to medium-sized HPPs in Europe with design discharges $Q_{d} \leq 120 \mathrm{~m}^{3} \mathrm{~s}^{-1}$ were equipped with horizontal bar rack bypass systems in the past decade [1,2]. Nevertheless, there is still a lack of systematic studies on the hydrodynamic optimization and verification of these state-of-the-art downstream fish guidance structures.

Downstream fish passage measures are classified as physical barriers, mechanical behavioral barriers, sensory behavioral barriers, collecting systems, fish-friendly turbines, and fish-friendly HPP operations [1,3-6]. Considering the limited number of monitoring studies, it is still necessary to assess the level of fish protection in European rivers by the application of any of these measures. 
Early laboratory and field studies on fish downstream migration have been mainly conducted in the USA. They focused on the application of fish guidance structures with vertical bars such as Louvers and angled bar racks, which act as mechanical behavioral barriers for American fish species, for example [7-9]. The clear bar spacing of such mechanical behavioral barriers typically ranges between 25 and $100 \mathrm{~mm}$. They are therefore theoretically permeable for most fish, but they modify the near-structure flow field, which affects the fish behavior and guides them to the bypass [10]. This modified flow field usually negatively affects the head losses and the turbine admission flow $[6,11]$. These negative effects can be mitigated by using curved instead of rectangular bars [12,13], but their fish guidance efficiency and practical application have yet to be proven. Physical barriers are characterized by small clear bar spacings ranging between 10 and $30 \mathrm{~mm}$, such that they are physically impermeable for the majority of fish. They can be installed either (a) perpendicular to the approach flow $\left(\alpha=\gamma=90^{\circ}\right)$, (b) inclined with a vertical angle $\gamma<90^{\circ}$, or (c) angled with a horizontal angle $\alpha<90^{\circ}$ (Figure 1) [1]. For the protection of a wide range of fish species, the flow velocity component normal to the rack $\left(V_{n}\right)$ should not exceed $0.5 \mathrm{~m} \mathrm{~s}^{-1}$ to avoid fish impingement and thus fish injuries $[1,14,15]$. Because approach flow velocities at HPPs are typically larger than $0.5 \mathrm{~m} \mathrm{~s}^{-1}$ and a guidance effect towards a bypass is missing, physical barriers oriented perpendicular to the approach flow (Figure 1a) are often unsuitable [16].

(a)

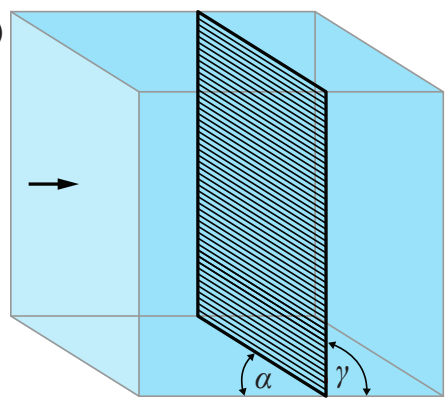

(b)

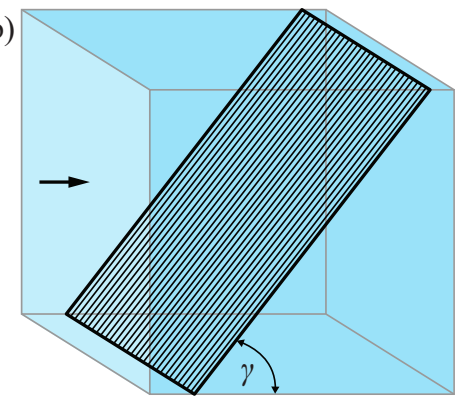

(c)

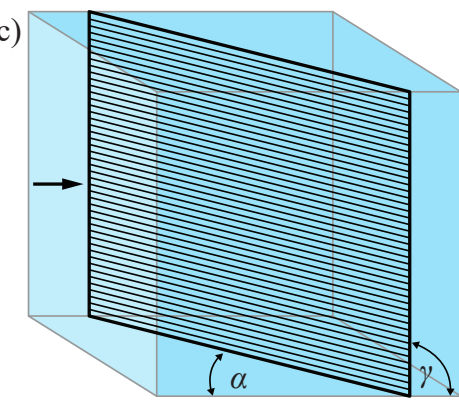

Figure 1. Rack layouts: (a) perpendicular, (b) inclined, and (c) angled to the approach flow; adapted from [6]. $\alpha$ : horizontal approach flow angle, $\gamma$ : rack inclination angle.

Since the construction of the first horizontal bar rack (HBR) with a specific focus on fish protection in 2006 at HPP Halle-Planena in Germany [1], these racks have become state-of-the-art for fish protection at small- to medium-sized HPPs $\left(Q_{d} \leq 120 \mathrm{~m}^{3} \mathrm{~s}^{-1}\right)$ in multiple countries. On the basis of experiences at several pilot HPPs, Ebel [1] specified a number of design guidelines: The horizontal approach flow angle $\alpha$ is selected to match the swimming capabilities and life stage of the relevant target fish species. Approach flow velocities, typically varying between $U_{0}=0.40$ and $0.80 \mathrm{~m} \mathrm{~s}^{-1}$, lead to $\alpha=20^{\circ}-40^{\circ}$. The rack angle is therefore a compromise between limiting $V_{n}$ on the one hand and the rack length on the other hand. The clear bar spacing $s_{b}$ of such physical barriers depends on the target fish species, typically resulting in a recommendation of $s_{b} \leq 15 \mathrm{~mm}$ [1].

The hydraulic losses of different HPP intake rack types were mainly investigated in physical models. Kirschmer [17] conducted 1:1 scaled laboratory experiments with perpendicular and inclined trash racks with different bar shapes (Figure 1a,b) and proposed an equation to estimate the rack head loss coefficient. Other authors such as Zimmermann [18], Meusburger [19], and Raynal et al. [15] built upon the equation of Kirschmer [17] by including characteristics such as partial clogging, overlays, and angled approach flows. However, up to now, proof is missing that these equations, developed for traditional trash racks with typically vertical bars, are suitable for head loss estimations of HBRs. Therefore, Maager [20] and Albayrak et al. [21] experimentally investigated the hydraulics of HBRs in a 1:2 Froude-scaled model for a wide range of basic parameters, including $\alpha=30^{\circ}$ and $45^{\circ} ; s_{b}=10,20$, and $30 \mathrm{~mm}$ (prototype dimensions); two different bar depths; and various overlay configurations. Their studies were limited to rectangular bars and rectangular bars with a rounded tip ("one-side rounded bars"). The latter were investigated for $\alpha=30^{\circ}$ only. Böttcher et al. [22] studied angled racks with 
horizontally aligned, cylindrical bars without overlays in a 1:2 Froude-scaled model. Racks with $\alpha=$ $30^{\circ}, 45^{\circ}$, and $90^{\circ}$ and $s_{b}=10,20$, and $30 \mathrm{~mm}$ (prototype dimensions) were investigated. All laboratory studies presented so far focused on sectional models, where only a section of the rack was investigated. Other associated structures such as a bypass for fish downstream migration or an adjacent weir were not included in these models. Some studies such as Berger [23] and Szabo-Meszaros et al. [24] focused on physical models of HBRs including a bypass, which makes it difficult to compare the head loss coefficients obtained in these studies with the losses of sectional models.

This paper reports the results of an experimental investigation of head losses of HBRs at different HPP layouts for a large number of rack configurations with and without overlays and up-to-date bar shapes, which are commonly used at modern HBRs, whereas the accompanying paper focuses on the velocity fields at HBRs [25].

\section{Experimentation}

\subsection{Test Setup}

The experiments were conducted in a $7.60 \mathrm{~m}$ long, $w_{c h}=0.50 \mathrm{~m}$ wide, and $0.70 \mathrm{~m}$ deep laboratory channel (Figures 2 and 3a) as a sectional model with 1:1 Froude-scaled model racks. Therefore, the individual bars were on a prototype scale, but only a section of the rack was modelled. The channel bottom and back wall were made of PVC (polyvinyl chloride), whereas the front wall was made of glass to allow for visual observations. The discharge of the closed water circulation system was controlled with a gate valve and measured with a magnetic-inductive flow meter. To achieve symmetrical approach flow conditions, a honeycomb flow straightener was placed at the channel inlet. Two $1 \mathrm{~m}$ long hard foam floaters were used to reduce surface waves. The water level was controlled with a downstream flap gate, creating a free overfall into the outlet basin. The measurement traverse carried an ultrasonic distance sensor, and the downstream rack end was positioned $4.2 \mathrm{~m}$ downstream of the honeycomb flow straightener. The coordinate system was defined as $x, y$, and $z$ for the streamwise, transversal, and vertical coordinates, respectively. The origin was set at the bottom of the right channel wall at the downstream rack end (Figure 3a). The bypass flow was neglected in the physical model as it is typically in the range of $2-5 \%$ of the total HPP discharge [1], and has therefore only a small effect on the hydraulic losses. To investigate the effect of the HPP layout, additional experiments were carried out with larger approach flow widths $w_{o}$ and a sharp contraction to the width of the turbine intake $w_{d s}$ downstream of the HBR, thereby representing block-type HPPs (Figure 3b). The entire discharge was diverted through the rack, so that the layout corresponded to an abrupt contraction.

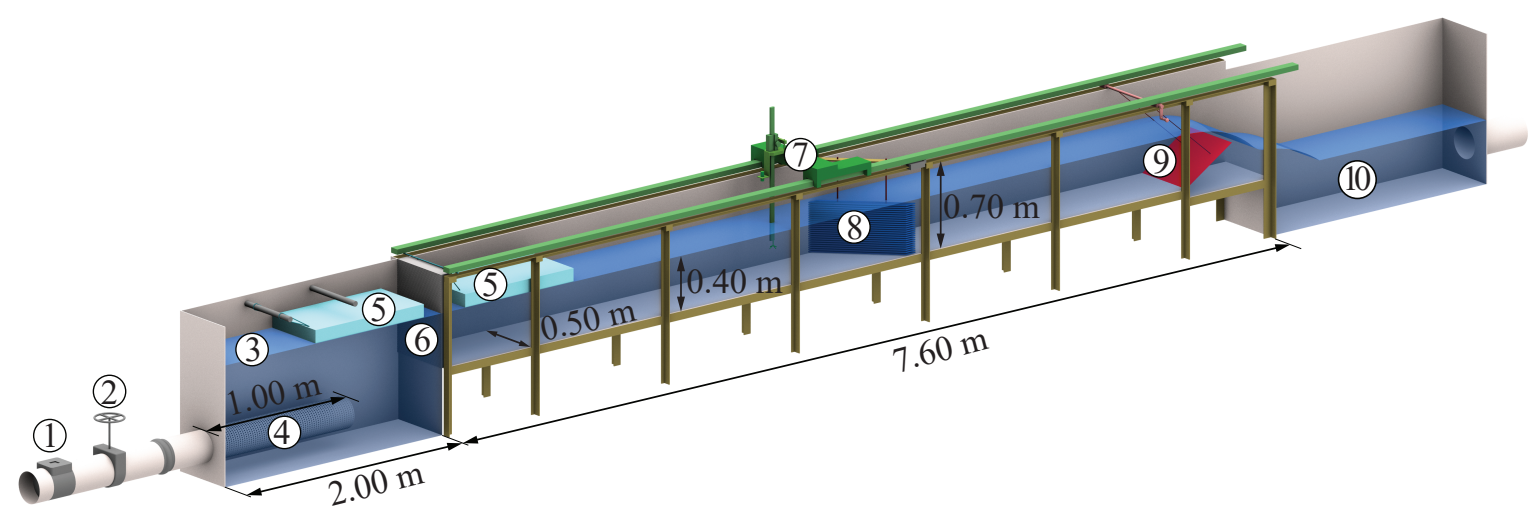

Figure 2. Sketch of the experimental channel for a diversion hydropower plant setup including: (1) magnetic-inductive flow meter, (2) gate valve, (3) inlet tank, (4) perforated inlet pipe, (5) floater, (6) honeycomb flow straightener, 7 traverse system and measurement cart carrying an ultrasonic distance sensor, (8) horizontal bar rack, (9) flap gate, and (10) outlet basin. 

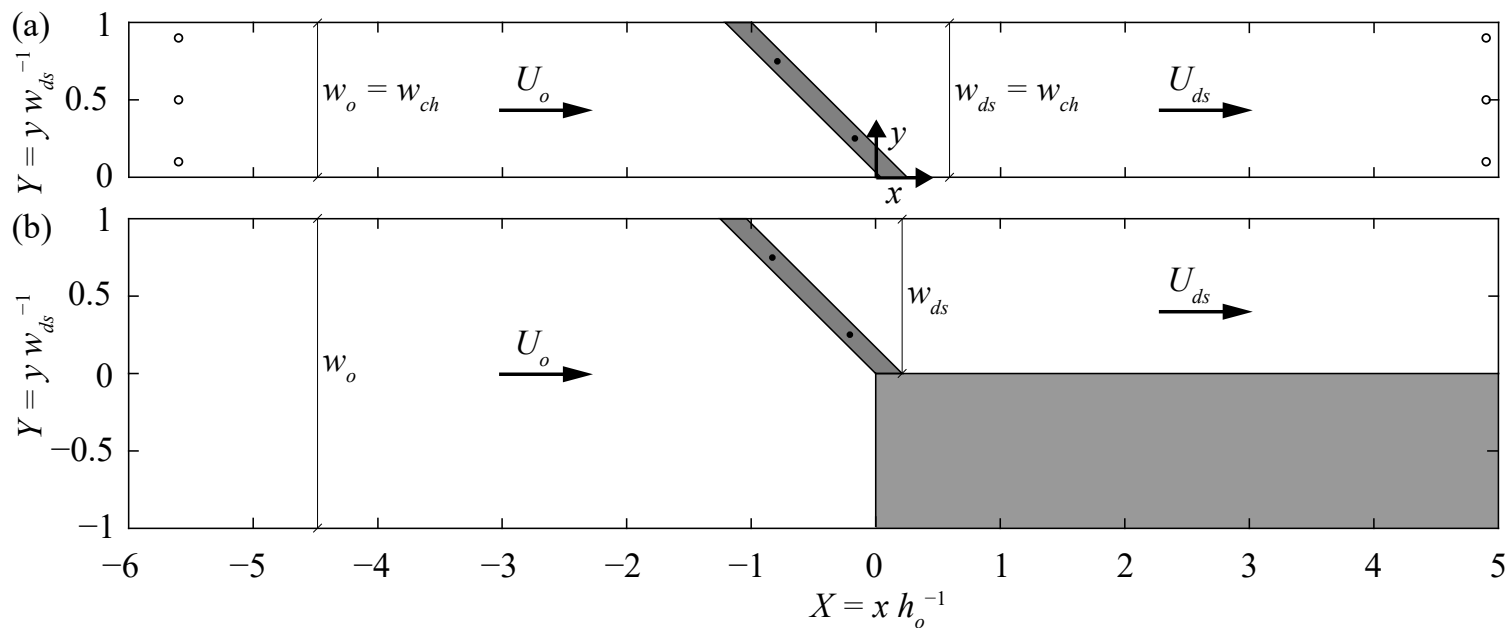

Figure 3. Channel top view with (a) coordinate system and measurement locations of a diversion hydropower plant and (b) configuration of a block-type hydropower plant (here $w_{o} w_{d s}{ }^{-1}=2.0$ ); the location of the vertical tie-bars is indicated with filled circles $(\bullet)$ and the ultrasonic distance sensor measurement locations with circle outlines (o); $w_{c h}$ : constant channel width, $w_{0}$ : upstream channel width, $w_{d s}$ : downstream channel width, $U_{0}$ : mean upstream approach flow velocity from continuity, $U_{d s}$ : mean downstream flow velocity, $x$ : streamwise coordinate, $X$ : normalized streamwise coordinate, $y$ : transversal coordinate, $Y$ : normalized transversal coordinate, $h_{0}$ : approach flow depth.

The measurement accuracy of the magnetic-inductive flow meter was $\pm 0.5 \%$. The sampling rate of the ultrasonic distance sensor was kept constant at $100 \mathrm{~Hz}$ with a repetition accuracy of $<0.5 \mathrm{~mm}$. The maximum temperature drift was $2 \%$ of the distance between the sensor itself and the measured object. The ultrasonic distance sensor measurements were confirmed with point gauge measurements.

The racks were made of aluminum and consisted of a $t_{b p}=10 \mathrm{~mm}$ thick bottom plate (subscript $b p$ ) and up to 22 bars (subscript $b$ ), depending on the selected bar spacing. The bars were assembled on two threaded bars ("vertical tie-bars") located at $Y=y w_{d s}{ }^{-1}=0.25$ and 0.75 . They are indicated as filled circles (•) in Figure 3a,b. The bar spacing was adjusted with cylindrical spacers (subscript $s$ ) with an outer diameter of $15 \mathrm{~mm}$. To mount the bottom plate and all bar ends flush with the channel walls, they were cut with the respective horizontal approach flow angle $\alpha$. On the basis of measurements on 13 different days, the average friction loss within the $l_{c h}=4.2 \mathrm{~m}$ long channel section without a rack was determined as $\Delta h_{f}=1.7 \mathrm{~mm}$, which corresponds to a friction slope of $0.40 \%$, with a standard deviation of $\sigma=0.2 \mathrm{~mm}$.

\subsection{Parameter Range and Test Program}

Head losses were determined for a range of rack and bar parameters representing the geometric characteristics of HBRs. Four bar shapes, commonly used for HBRs, were investigated, namely, (S1) rectangular bars, (S2) rectangular bars with a circular tip, (S3) bars with an ellipsoidal tip and tail, and (S4) foil-shaped bars (Figures 4 and 5). In contrast to the rectangular bars (S1), the thickness of the bars S2-S4 reduces from tip to tail, which makes them hydrodynamically efficient. These bars (S2-S4) are termed hydrodynamic bars hereafter. The model HBRs consisted of bars in prototype dimensions (scale 1:1) with a bar thickness $t_{b}=8 \mathrm{~mm}$ and bar depth $d_{b}=60 \mathrm{~mm}$ in flow direction (Figure 4 ). The bar thickness and the clear bar spacing $s_{b}$ are defined as the streamwise projection of both values, that is, the maximum bar thickness and the smallest spacing between two bars, respectively (Figure 5). The relative bar depth $D_{b}=d_{b} t_{b}{ }^{-1}$ is defined as the ratio between bar depth and bar thickness. The bar thickness at mid cross section (the mounting location) was $t_{b, m}=5 \mathrm{~mm}$, except for the rectangular bars (S1), where $t_{b, m}=8 \mathrm{~mm}$ (Figure 4). The relative bottom (subscript Bo) and top (subscript To) overlay heights $\left(H_{B o}=h_{B o} h_{o}^{-1}\right.$ and $\left.H_{T o}=h_{T o} h_{o}^{-1}\right)$ were calculated using the respective bottom and top overlay heights $\left(h_{B o}, h_{T o}\right)$ and the approach flow depth $h_{0}$ for normalization. The total overlay height was 
defined as $H_{O v}=H_{B o}+H_{T o}$. The top overlay height $h_{T o}$ was measured as the distance between the approach flow water level $z=h_{o}$ and the lower overlay tip, and therefore neglected the flow stagnation height at the overlay (Figure 5). The horizontal approach flow angle $\alpha$ was defined as the horizontal angle between the rack and the main flow (Figure 5). The approach flow angles $\alpha=30^{\circ}$ and $45^{\circ}$ were investigated for all bar shapes and bar spacings.

(a) $\mathrm{S} 1$
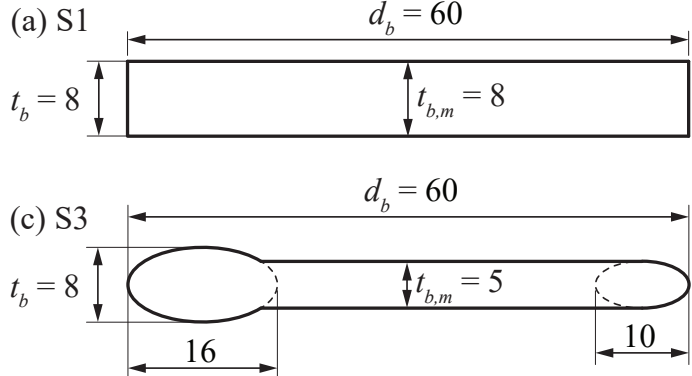

(b) S2
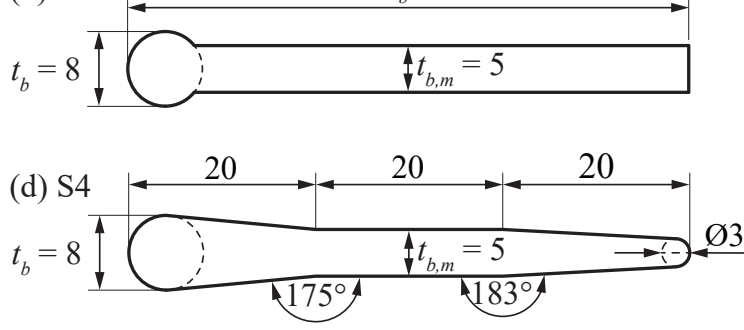

Figure 4. Dimensions of investigated bar shapes (a) rectangular (S1), (b) circular tip (S2), (c) ellipsoidal tip and tail (S3), and (d) foil-shaped (S4); all measures in millimeters. $t_{b}$ : bar thickness at thickest point, $t_{b, m}$ : bar thickness at mid cross section, $d_{b}$ : bar depth.

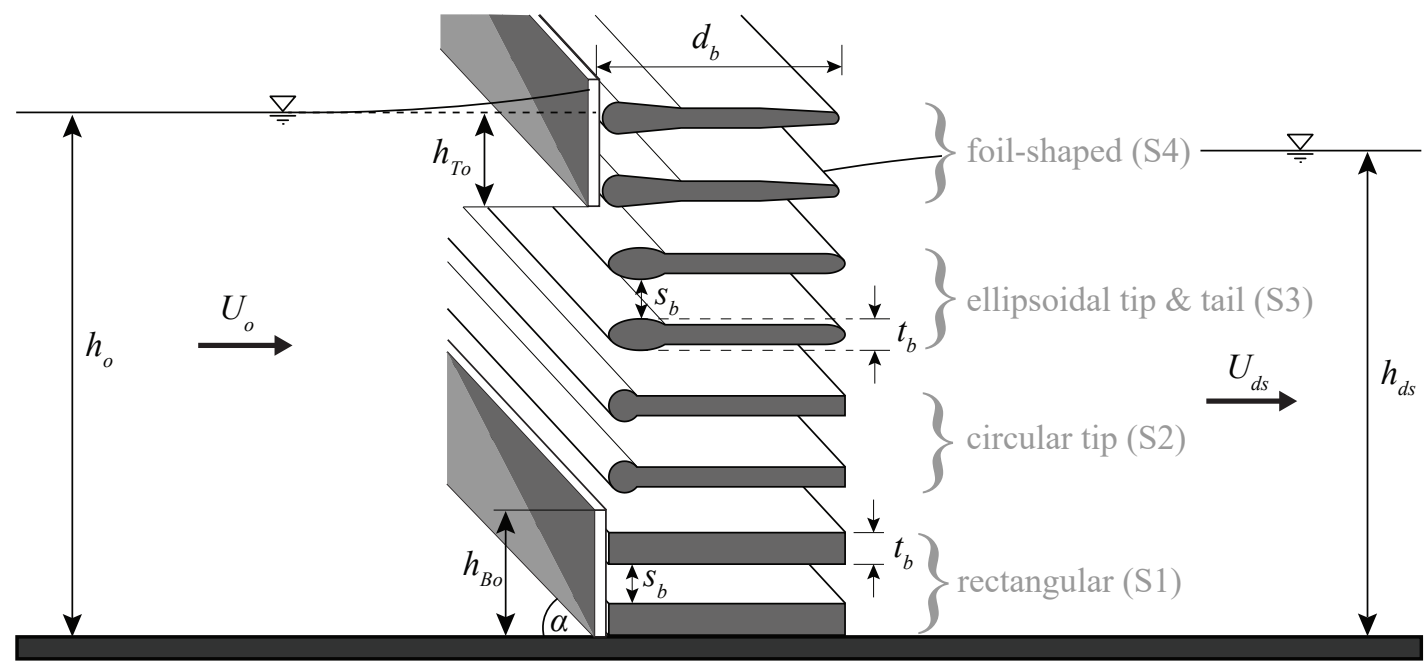

Figure 5. Definition sketch of the governing rack parameters. $h_{0}$ : approach flow depth, $h_{d s}$ : downstream flow depth, $U_{0}$ : mean upstream approach flow velocity from continuity, $U_{d s}$ : mean downstream flow velocity, $h_{B o}$ : bottom overlay height, $h_{T o}$ : top overlay height, $s_{b}$ : clear bar spacing, $t_{b}$ : bar thickness at thickest point, $d_{b}$ : bar depth.

For the head loss measurements, the clear bar spacing varied between $s_{b}=10,20$, and $30 \mathrm{~mm}$. Each rack configuration was tested without overlays, and with six different overlay setups: (1) $H_{B o}=$ $0.1, H_{T o}=0$; (2) $H_{B o}=0, H_{T o}=0.1$; (3) $H_{B o}=0.2, H_{T o}=0$; (4) $H_{B o}=0, H_{T o}=0.2$; (5) $H_{B o}=H_{T o}=0.1\left(H_{O v}\right.$ =0.2); and (6) $H_{B o}=H_{T o}=0.2\left(H_{O v}=0.4\right)$. In an additional set of experiments, an approach flow angle of $\alpha=90^{\circ}$ and the effect of the relative bar depth $D_{b}$ were investigated. Measurements were conducted for (a) S1-bars with $s_{b}=10,20$, and $30 \mathrm{~mm}$ and (b) S2-bars with $s_{b}=20 \mathrm{~mm}$. The effect of the relative bar depth $D_{b}=3.5,5.5,7.5,9.5,12,15$ was investigated with S2-bars for (a) $\alpha=90^{\circ}$ and $s_{b}=20 \mathrm{~mm}$ and (b) $\alpha$ $=30^{\circ}$ and $s_{b}=10,20$, and $30 \mathrm{~mm}$. Contraction ratios of $w_{o} w_{d s}{ }^{-1}=1.25,1.5$, and 2.0 were studied for the bar shape $S 4, s_{b}=20 \mathrm{~mm}$, and $\alpha=30^{\circ}$ and $45^{\circ}$ with all overlay configurations listed above. A multiple linear regression was performed to develop head loss prediction equations. These equations were then validated with the data of Maager [20] and Albayrak et al. [21], and Böttcher et al. [22]. 
The total blocking ratio $B R$ of the model rack was calculated as the sum of the blocking ratio due to the horizontal bars $\left(B R_{b}\right)$, the spacers $\left(B R_{s}\right)$, and the bottom plate $\left(B R_{b p}\right)$ with Equation (1) as

$$
B R=B R_{b}+B R_{s}+B R_{b p}=\left(n_{b} \frac{t_{b}}{h_{o}}\right)+\left(n_{s} \frac{\left(s_{b}+t_{b}-t_{b, m}\right) n_{v} t_{s}}{h_{o} w_{c h}}\right)+\left(\frac{t_{b p}}{h_{o}}\right),
$$

where $n_{b}$ is the number of horizontal bars $(-), n_{s}$ is the number of spacers per vertical tie-bar $(-)$, $n_{v}$ is the number of vertical tie-bars (-), and $t_{s}$ is the spacer thickness (outer diameter). Depending on the rack configuration, the uppermost horizontal bar or spacer was only partially submerged, such that $n_{b}$ or $n_{s}$ was not a whole number. The exact values of $B R$ are listed in Table 1. Because the bar thickness reduced from tip to tail for the hydrodynamic bars (S2-S4), a larger proportion of the vertical tie-bars (spacers) was exposed to the flow, thus leading to slightly larger BR for S2-S4 in comparison to $\mathrm{S} 1$ (Table 1). For a preliminary design, the blocking ratio of the bottom plate $B R_{b p}$ can be neglected, and a constant bar thickness can be assumed, leading to the approximate blocking ratio $B R^{*} \cong\left(s_{b}+t_{b}\right)^{-1}\left(t_{b}+s_{b} n_{v} t_{s} w_{c h}{ }^{-1}\right)$. The deviation to the exact blocking ratio $\left|B R-B R^{*}\right| B R^{-1}$ was then $0.8 \%$ to $6.5 \%$, depending on the configuration.

Table 1. Exact blocking ratios $B R$ of the model racks and approximate blocking ratios $B R^{*}$ for a preliminary design of racks with different clear bar spacing $s_{b}$ and bar shapes S1-S4 (cf. Figure 4)

\begin{tabular}{cccc}
\hline $\boldsymbol{s}_{\boldsymbol{b}} \mathbf{( m m )}$ & $\boldsymbol{B R}$ of $\mathbf{S 1}$ & $\boldsymbol{B R}$ of $\mathbf{S 2}-\mathbf{S 4}$ & $\boldsymbol{B R}^{*}$ of $\mathbf{S 1 - S 4}$ \\
\hline 10 & 0.482 & 0.492 & 0.478 \\
20 & 0.342 & 0.348 & 0.329 \\
30 & 0.272 & 0.276 & 0.258 \\
\hline
\end{tabular}

\subsection{Experimental Procedure}

The flow depths were measured using an ultrasonic distance sensor at three transversal locations upstream (subscript $\left.o ; X=x h_{0}{ }^{-1}=-5.6 ; Y=y w_{d s}{ }^{-1}=0.1,0.5,0.9\right)$ and three transversal locations downstream (subscript $d s ; X=4.9 ; Y=0.1,0.5,0.9$ ) of the rack (circle outlines (o) in Figure 3a) with a measurement duration of $30 \mathrm{~s}$. To account for measurement inaccuracies due to air temperature variations, the reference distance between the measurement cart and the channel bottom was measured prior to each test series. For each rack configuration, the downstream flap gate was adjusted to obtain $h_{o}=0.40 \mathrm{~m}$. The corresponding flow velocities $U_{o}$ and $U_{d s}$ were determined from continuity (Equation (2)) and the hydraulic head loss $\Delta h_{R}$ caused by the rack was calculated with the Bernoulli equation (Equation (3)):

$$
\begin{gathered}
U_{o}=\frac{Q}{w_{o} h_{o}}, U_{d s}=\frac{Q}{w_{d s} h_{d s}} \\
\Delta h_{R}=h_{o}+\frac{U_{o}^{2}}{2 g}-h_{d s}-\frac{U_{d s}^{2}}{2 g}-\Delta h_{f} .
\end{gathered}
$$

The friction losses were measured following the same experimental procedure as for the rack head losses, but without a rack installed (Section 2.1). The head loss prediction equations presented below are intended to be applicable for various HPP layouts and operational conditions. The head loss was therefore related to the theoretical average flow velocity with Equation (4) as

$$
U_{t h}=\frac{Q_{t}}{w_{d s} h_{o}}
$$

where $Q_{t}$ is the turbine discharge $\left(\mathrm{m}^{3} \mathrm{~s}^{-1}\right)$. Independent of the HPP layout, $U_{t h} \approx U_{d s}$ for small head losses. At diversion HPP setups in a straight channel with constant $w_{c h}$ and without a bypass, $U_{t h}=U_{o}$ (Figure 3a). By using $U_{t h}$ instead of $U_{o}$ or $U_{d s}$, the assessment was independent of potential weir and 
bypass discharge in case of a block-type HPPs (Figure 3b), but still accounted for $\Delta h_{R}$. The resulting rack head loss coefficient $\xi_{R}$ was then determined with Equation (5):

$$
\xi_{R}=\Delta h_{R} \frac{2 g}{U_{t h}^{2}} .
$$

\subsection{Measurement Uncertainties}

Measurement uncertainties were caused by the magnetic-inductive flow meter and the ultrasonic distance sensor, as described above. Their effect on $\xi_{R}$ was assessed with a Monte Carlo simulation with $10^{7}$ model runs. This uncertainty estimation included the magnetic-inductive flow meter measurements, the ultrasonic distance sensor reference measurements to the bottom, and the water level measurements up- and downstream of the rack. The required input probability density functions were experimentally determined from $480 \mathrm{~min}$ of measurement duration. The measured time series was divided into 960 values, each corresponding to a $30 \mathrm{~s}$ time average. Finally, a normal distribution was fitted to these data. The probability density function of the ultrasonic distance sensor reference measurements to the channel bottom resulted from 60 min of measurement duration, which was split up into 360 values corresponding to a $10 \mathrm{~s}$ time average. The resulting standard deviations of the ultrasonic distance sensor (UDS) and the magnetic-inductive flow meter (MID) were $\sigma_{\mathrm{UDS} \text {, bottom }}=1.0 \mathrm{~mm}, \sigma_{\mathrm{UDS} \text {, water }}=$ $2.7 \mathrm{~mm}, \sigma_{\mathrm{MID}}=2.5 \mathrm{~L} \mathrm{~s}^{-1}$. These measurement uncertainties led to a 95\% quantile of $\xi_{R}= \pm 0.035$, independent of the rack configuration.

\subsection{Model Effects}

Because the bars were modelled on prototype-scale, potential scale effects were precluded. However, as the physical model corresponded to only a section of a prototype structure, so-called model effects could occur, for instance effects caused by the channel boundaries. The velocity profile created by these boundaries may then differ from a prototype situation. Therefore, the effect of a variation in $h_{o}$ and $U_{t h}$ was investigated for racks with S1- and S4-bars, $\alpha=45^{\circ}$, and $s_{b}=20 \mathrm{~mm}(B R \approx$ $0.35)$ at the diversion HPP setup $\left(U_{o}=U_{t h}\right)$.

Figure $6 \mathrm{a}, \mathrm{b}$ shows the rack head loss coefficient $\xi_{R}$ as a function of $h_{0}$ for the bar shapes S1 and S4, respectively, with $U_{t h}=0.50 \mathrm{~m} \mathrm{~s}^{-1}$. For both bar shapes, $\xi_{R}$ was independent of the approach flow depth if $h_{o} \geq 0.20 \mathrm{~m}\left(h_{o} \geq 25 t_{b}\right)$. Because the channel walls slightly deformed for $h_{0} \geq 0.40 \mathrm{~m}$ due to the hydrostatic load, $h_{o}=0.40 \mathrm{~m}$ (corresponding to a flow depth to bar thickness ratio of $h_{o} t_{b}{ }^{-1}=50$ ) was selected as an optimum flow depth in terms of experimental handling. Figure $6 c$,d shows $\xi_{R}$ as a function of $U_{t h}$ for bar shapes S1 and S4, respectively, for constant $h_{0}=0.40 \mathrm{~m}$. The coefficient $\xi_{R}$ was independent of $U_{t h}$ for $U_{t h} \geq 0.2 \mathrm{~m} \mathrm{~s}^{-1}$, corresponding to a bar Reynolds number $\mathrm{R}_{b}=t_{b} U_{t h} v^{-1}$ $\geq 1600$, with $v=1.01 \times 10^{-6} \mathrm{~m}^{2} \mathrm{~s}^{-1}$ as the kinematic viscosity of water at $20^{\circ} \mathrm{C}$. For $U_{t h}>0.6 \mathrm{~m} \mathrm{~s}^{-1}$, surface waves reduced the measurement accuracy. Therefore, all further main experiments were conducted at a constant theoretical flow velocity of $U_{t h}=0.5 \mathrm{~m} \mathrm{~s}^{-1}\left(Q_{t}=0.1 \mathrm{~m}^{3} \mathrm{~s}^{-1}\right.$, Equation (4)) with $\mathrm{R}_{b}=4000$, Froude number $\mathrm{F}=U_{t h} g^{-0.5} h_{0}{ }^{-0.5}=0.25$, and Reynolds number $\mathrm{R}=4 R_{h} U_{t h} v^{-1}=$ $3 \cdot 10^{5}$, involving the hydraulic radius $R_{h}=h w_{c h}\left(2 h+w_{c h}\right)^{-1}$. This flow velocity was an optimum value, thereby representing prototype conditions. Furthermore, the selected parameters were in excess of the threshold values $h_{0} t_{b}{ }^{-1} \geq 40$ and $\mathrm{R}_{b} \geq 1500$ to avoid model effects for different rack types specified in the literature $[11,12,18,19]$. 

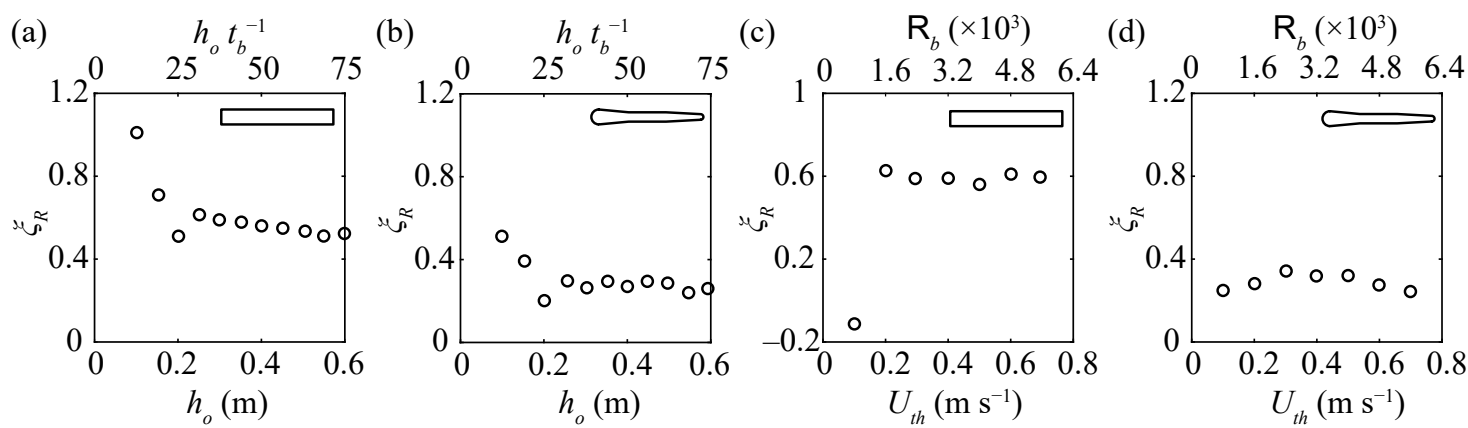

Figure 6. Rack head loss coefficients $\xi_{R}$ as a function of approach flow depth $h_{0}$ with constant theoretical average flow velocity $U_{t h}=0.50 \mathrm{~m} \mathrm{~s}^{-1}$ for bar shapes (a) S1 and (b) S4, and as a function of the theoretical average flow velocity $U_{t h}$ with constant approach flow depth $h_{o}=0.40 \mathrm{~m}$ for bar shapes (c) S1 and (d) S4. $t_{b}$ : bar thickness at thickest point, $\mathrm{R}_{b}$ : bar Reynolds number.

\section{Results}

\subsection{General Observations}

Figure 7 shows the rack head loss coefficient $\xi_{R}$ as a function of (a) the bar shape $S$, (b) the blocking ratio $(B R)$, and (c) the approach flow angle $\alpha$ for all tested rack configurations without overlays and $D_{b}=7.5$. Depending on the individual rack configuration, the determined values ranged from $\xi_{R}=$ 0.17-2.53 without overlays (Figure 7) and up to $\xi_{R}=8.57$ with overlays (not shown in Figure 7). Three governing effects were observed:

(I) $\quad \xi_{R}$ reduced from rectangular to hydrodynamic bars for all $s_{b}$ (Figure 7a). The difference between S1 and S2 was large, whereas S3 and S4 led to similar $\xi_{R}$ as for S2.

(II) $\xi_{R}$ increased with increasing $B R$, corresponding to smaller $s_{b}$, for all bar shapes and approach flow angles (Figure 7b). This effect was larger for S1 as compared to S2, S3, and S4.

(III) $\xi_{R}$ increased with increasing $\alpha$ (Figure 7c). The angle effect was most pronounced for S1 with $s_{b}=$ $10 \mathrm{~mm}(B R \approx 0.49)$ and almost negligible for $\mathrm{S} 4$ with $s_{b}=30 \mathrm{~mm}(B R \approx 0.28)$.
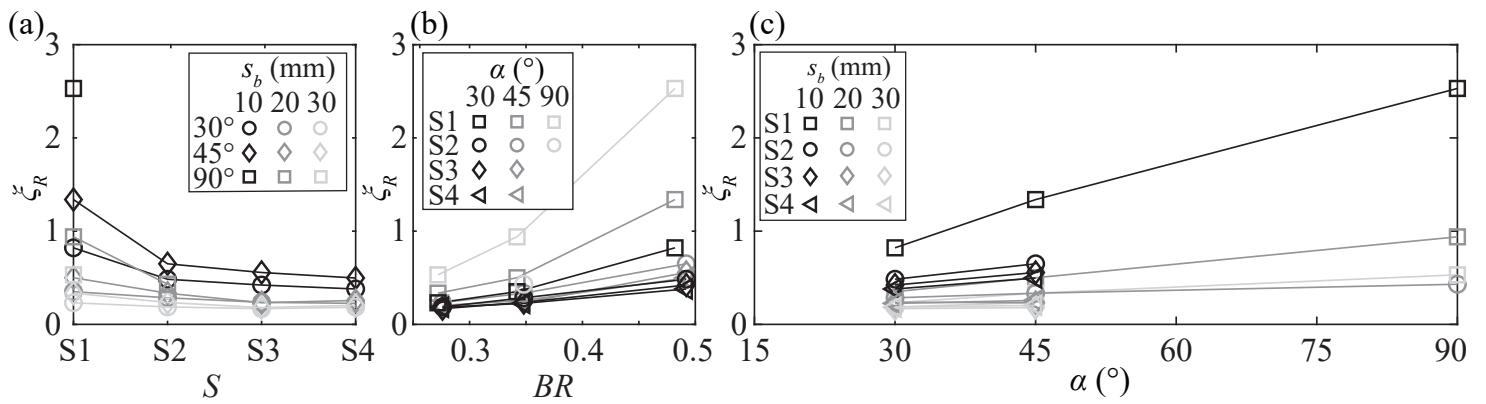

Figure 7. Rack head loss coefficients $\xi_{R}$ as a function of (a) bar shape S1-S4, (b) blocking ratio BR, and (c) horizontal approach flow angle $\alpha$ for all tested rack configurations without overlays and a relative bar depth of $D_{b}=7.5$. $s_{b}$ : clear bar spacing.

The effect of overlays is not included in Figure 7 because there were superposed effects of the overlay layout, the bar shape, $B R$, and $\alpha$. The overlay effect is therefore individually described in detail below.

Figure 8 shows $\xi_{R}$ as a function of the relative bar depth $D_{b}$ with S2-bars for (a) $\alpha=90^{\circ}$ and (b) $\alpha$ $=30^{\circ}$. For $\alpha=90^{\circ}, D_{b}$ had no significant effect on $\xi_{R}$ (Figure 8a). In contrast, for $\alpha=30^{\circ}$, shorter bars led to smaller $\xi_{R}$ (Figure 8b). This effect was more pronounced for $s_{b}=10 \mathrm{~mm}$ than for $s_{b}=20$ and $30 \mathrm{~mm}$. Although the $\xi_{R}$ values were almost identical for short bars with $D_{b}=3.5$ and $D_{b}=5.5$, they increased linearly between $D_{b}=5.5$ and $D_{b}=15$ (Figure 8b). Figure 8 also shows that the effect of $D_{b}$ 
on $\xi_{R}$ was similar for all overlay configurations. Overall, within the typical application range of HBRs $\left(\alpha=30^{\circ}, D_{b}=5-10, H_{O v}<0.4\right)$, the effect of $D_{b}$ on $\xi_{R}$ was small, that is, $\leq \pm 10 \%$.
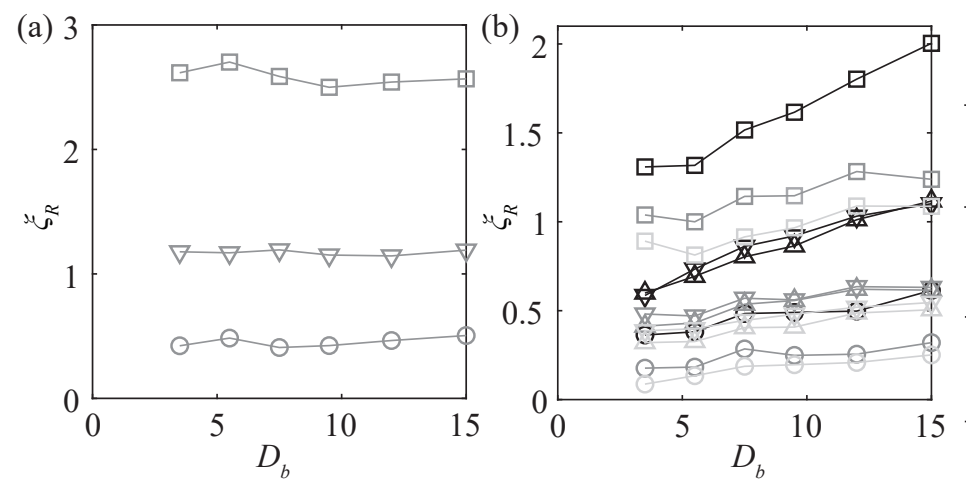

$$
\begin{aligned}
& s_{b}=10 \mathrm{~mm} \quad s_{b}=20 \mathrm{~mm} \quad s_{b}=30 \mathrm{~mm} \\
& \square \begin{array}{r}
H_{B o}=0.2 \\
H_{T o}=0.2
\end{array} \square \begin{array}{l}
H_{B o}=0.2 \\
H_{T o}=0.2
\end{array} \square \begin{array}{l}
H_{B o}=0.2 \\
H_{T o}=0.2
\end{array} \\
& \triangle \begin{array}{l}
H_{B o}=0.2 \\
H_{T o}=0
\end{array} \triangle \begin{array}{l}
H_{B o}=0.2 \\
H_{T o}=0
\end{array} \triangle \begin{array}{l}
H_{B o}=0.2 \\
H_{T o}=0
\end{array}
\end{aligned}
$$

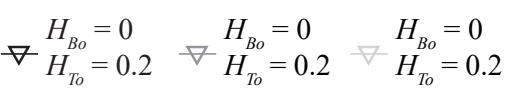

$$
\begin{aligned}
& \begin{array}{ccc}
H_{B o}=0 & H_{B o}=0 & H_{B o}=0 \\
H_{T o}=0 & \bullet H_{T o}=0 & H_{T o}=0
\end{array}
\end{aligned}
$$

Figure 8. Rack head loss coefficients $\xi_{R}$ as a function of relative bar depth $D_{b}$ for S2-bars with approach flow angle of $(\mathbf{a}) \alpha=90^{\circ}$ and (b) $\alpha=30^{\circ}$ and different overlay configurations. $s_{b}$ : clear bar spacing, $H_{B o}$ : relative bottom overlay height, $H_{T o}$ : relative top overlay height.

\subsection{General Equation for Head Loss Prediction}

To account for the governing basic parameters, the rack head loss coefficient $\xi_{R}$ was defined as the product of five individual coefficients: blocking ratio coefficient $C_{B R}$, approach flow angle coefficient $C_{\alpha}$, bar shape coefficient $C_{S}$, bar depth coefficient $C_{D b}$, and overlay coefficient $C_{O v}$. On the basis of a curve fitting analysis for the hydrodynamic bars, Equation (6) was proposed to predict the head losses of HBRs with hydrodynamic bars. The computation of the individual coefficients is described in the following sections. The experimentally determined rack head loss coefficients $\xi_{R, m}$ (subscript $m=$ measured) were in good agreement with the predicted (subscript $p$ ) values $\xi_{R, p}$ on the basis of Equation (6) for S2-S4 without overlays (Figure 9a). The mean prediction error ( $\overline{P E}$, Equation (7)) was less than 22\% for all measurement data with S2-S4 (Figure 9b). The error bars show the 95\% quantile of the measurement uncertainty as described in Section 2.4. For $\xi_{R, m}>0.5$, the measurement uncertainties were small $(< \pm 7 \%)$, whereas they were relatively large for $\xi_{R, m}<0.2(> \pm 17.5 \%$; Figure $9 b)$. However, with HPP approach flow velocities in the range of $U_{0}=0.3-1.0 \mathrm{~m} \mathrm{~s}^{-1}$, the resulting total losses are small $\left(\Delta h_{R}=\xi_{R} U_{o}^{2}(2 g)^{-1} \approx 1.0 \mathrm{~cm}\right.$; with $U_{o}=1 \mathrm{~m} / \mathrm{s}$ and $\left.\xi_{R}=0.2\right)$ and this uncertainty becomes negligible for energy production. Equation (6) can also be applied for rectangular bars (S1) but then leads to a significant deviation for higher $\xi_{R, p}$ (Figure 9). Therefore, an alternative equation for rectangular bars is presented below, which is proposed to predict $\xi_{R}$ more accurately for S1-bars, accounting for the different hydraulic behavior of rectangular and hydrodynamic bars.

$$
\begin{gathered}
\xi_{R}=C_{B R} C_{\alpha} C_{S} C_{D b} C_{O v} \\
P E=\frac{\xi_{R, p}-\xi_{R, m}}{\xi_{R, m}} \times 100(\%) ; \overline{P E}=n^{-1} \sum|P E|,
\end{gathered}
$$

where $n$ is the number of data points.

\subsubsection{Blocking Ratio Coefficient $C_{B R}$}

An increasing blocking ratio decreases the hydraulically active area, whereas it increases the local flow velocity and thus the head losses. The blocking ratio coefficient was calculated with Equation (8) as

$$
C_{B R}=\frac{B R}{(1-B R)} .
$$


On the basis of the investigated parameter range of $B R$ (Table 1), the application limit is $0.25 \leq B R$ $\leq 0.50$, covering the significant range at prototype HPPs. Given a small bar spacing of $s_{b}=10 \mathrm{~mm}$, the corresponding high $B R \approx 0.5$ results in $C_{B R}=1.0$. This value reduces to $C_{B R}=0.33$ for low $B R=0.25$.
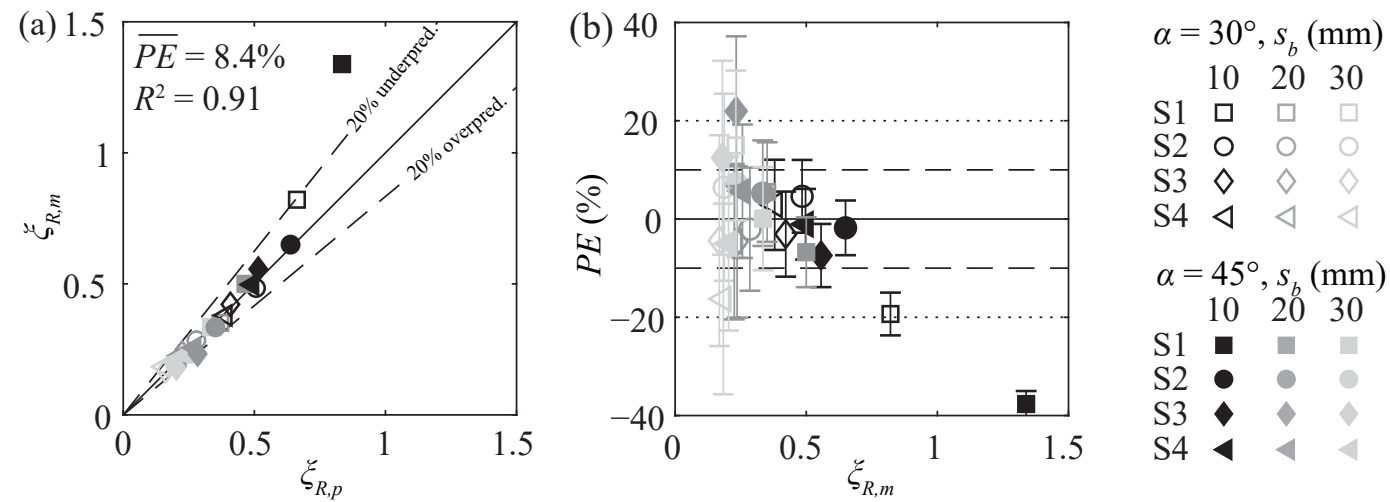

Figure 9. Rack head loss coefficients for configurations with S1-S4-bars without overlays with (a) comparison of predicted (Equation (6)) and measured values $\left(\xi_{R, p}, \xi_{R, m}\right)$ and (b) prediction errors $P E$ as a function of the measured rack head loss coefficients $\xi_{R, m} . \alpha$ : horizontal approach flow angle, $s_{b}$ : clear bar spacing.

\subsubsection{Approach Flow Angle Coefficient $C_{\alpha}$}

The approach flow angle $\alpha$ is a measure of the rack length and thus the hydraulically active area. A small $\alpha$ represents a longer rack and thus a large hydraulically active area, therefore reducing flow velocity and head losses. The approach flow angle coefficient was calculated with Equation (9) as

$$
C_{\alpha}=\sin (\alpha)^{2 / 3}
$$

For hydrodynamic bars, $C_{\alpha}$ was determined on the basis of experiments with $\alpha=30^{\circ}$ and $45^{\circ}$ and validated with $\alpha=90^{\circ}$ for S2 and $s_{b}=20 \mathrm{~mm}(B R \approx 0.35)$. The validation for $\alpha>45^{\circ}$, shown in Section 3.3, indicates an application range of Equation (9) of $\alpha=30^{\circ}-90^{\circ}$. For $\alpha=90^{\circ}, C_{\alpha}=1.0$, whereas for $\alpha=30^{\circ}$, it reduces to $C_{\alpha}=0.63$.

\subsubsection{Bar Shape Coefficient $C_{S}$}

Hydrodynamic bars minimize flow separation zones and therefore reduce energy dissipation due to vortex shedding and turbulence. The experimentally determined bar shape coefficients are presented in Table 2 for the four investigated bar shapes. These shape coefficients indicate that $\xi_{R}$ reduces on average by $\approx 27 \%$ from $\mathrm{S} 1$ to $\mathrm{S} 2$ and by $\approx 42 \%$ from $\mathrm{S} 1$ to $\mathrm{S} 3 / \mathrm{S} 4$.

Table 2. Investigated bar shapes S1-S4 and the corresponding bar shape coefficients $C_{S}$ (cf. Figure 4).

\begin{tabular}{|c|c|c|c|c|}
\hline Denotation & S1 & S2 & S3 & S4 \\
\hline \multicolumn{5}{|l|}{ Shape } \\
\hline$C_{S}$ & 1.13 & 0.83 & 0.67 & 0.64 \\
\hline
\end{tabular}

\subsubsection{Bar Depth Coefficient $C_{D b}$}

Shorter bars lead to reduced friction losses and therefore smaller $\xi_{R}$, as long as the bars are deep enough for the separated flow to reattach to the side face of the bars. The bar depth effect is accounted for with Equation (10). For the standard relative bar depth $D_{b}=7.5, C_{D b}=1$. Bars with $D_{b}<7.5$ lead to $C_{D b}<1$, whereas $D_{b}>7.5$ leads to $C_{D b}>1$. For an HBR with $\alpha=30^{\circ}, C_{D b}=0.90$ for $D_{b}=5$, and $C_{D b}=$ 1.10 for $D_{b}=10$. For $\alpha=90^{\circ}$, no significant effect of $D_{b}$ on $\xi_{R}$ was observed in the range of $D_{b}=3.5-15$ (Figure 8a). Therefore, $C_{D b}=1$ for $\alpha=90^{\circ}$ (Equation 10). The coefficient $C_{D b}$ linearly increases from $\alpha$ 
$=90^{\circ}$ to $\alpha=30^{\circ}$. The recommended application limit of Equation (10) is $5 \leq D_{b} \leq 15$, which covers the typical range of HBRs at prototype HPPs.

$$
C_{D b}=0.04\left(D_{b}-7.5\right)\left(\frac{90^{\circ}-\alpha}{60^{\circ}}\right)+1
$$

\subsubsection{Application of General Head Loss Equation to Rectangular Bars}

Equations (6) and (8)-(10) were developed for hydrodynamic bars. Additionally, a shape factor for S1-bars was determined by minimizing $\overline{P E}$ (Table 2), allowing for the application of the above equations for rectangular bars. However, the hydraulic processes at racks with rectangular bars significantly differ from those at racks with hydrodynamic bars. Because flow separations at the tip of rectangular bars additionally decrease the hydraulically active area between two bars, the $B R$ effect is more pronounced for S1-bars. Therefore, $\xi_{R}$ increases disproportionately for rectangular bars for larger $\alpha$ and smaller $s_{b}$ (Figure $7 \mathrm{~b}, \mathrm{c}$ ). The loss coefficient $\xi_{R, p}$ is underestimated by Equation (6) for S1, large $\alpha$, and small $s_{b}$ (Figure 9). Hence, Equation (11) is proposed to estimate $\xi_{R}$ for rectangular bars, where the larger effects of $\alpha$ and $s_{b}$ are taken into account with larger exponents.

$$
\xi_{R}=2.33\left(\frac{B R}{1-B R}\right)^{3 / 2} \sin (\alpha)^{4 / 3} C_{O v} C_{D b}
$$

In Figure 10, $\xi_{R, m}$ is compared to the predictions on the basis of Equation (6) (star-shaped symbols) and Equation (11) (square symbols). For small head loss coefficients ( $\left.\xi_{R} \leq 0.5\right)$, Equations (6) and (11) lead to similar $\xi_{R, p}$, whereas for $\xi_{R}>0.5$, Equation (6) underestimates $\xi_{R}$ for the S1-bars. Therefore, Equation (6) is recommended for racks with rectangular bars, only if $s_{b} \geq 20 \mathrm{~mm}$.

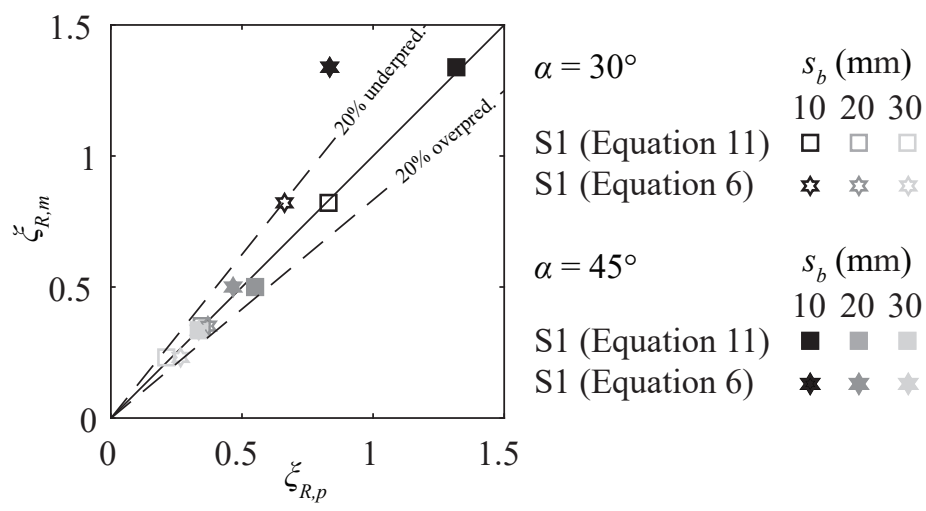

Figure 10. Comparison of measured rack head loss coefficients $\xi_{R, m}$ and predicted rack head loss coefficients $\xi_{R, p}$ with Equations (6) and (11) for racks with rectangular bars (S1). $\alpha$ : horizontal approach flow angle, $s_{b}$ : clear bar spacing.

A very good agreement of $\xi_{R, m}$ and $\xi_{R, p}$ results if Equation (6) is applied to hydrodynamic bars and in parallel Equation (11) for rectangular bars (Figure 11). Including all measurement data with $\alpha=$ $30^{\circ}$ and $45^{\circ}, \overline{P E}$ was only $5.8 \%$ with individual maximum deviations of $22 \%$.

\subsubsection{Overlay Coefficient $\mathrm{C}_{\mathrm{Ov}}$}

Overlays block a part of the cross section and thereby reduce the hydraulically active rack area. In addition, overlays create a strong flow deflection, which leads to additional losses. These effects are superposed with additional effects of the overlay layout, $B R, \alpha$, the bar shape, and the relative overlay height. The overlay coefficient therefore is $C_{O v}=f\left(C_{O L}, B R, \alpha, C_{S}, H_{O v}\right)$, where $C_{O L}$ is the overlay layout coefficient with $C_{O L}=1$ if either bottom or top overlays are applied and $C_{O L}=0.9$ for 
combined bottom and top overlays (Equation (12)). Equation (12) can be applied to calculate $C_{\mathrm{Ov}}$ in both Equations (6) and (11).

$$
C_{O v}=1+C_{O L}\left(\frac{1}{2} B R^{-2}+7.4 \sin (\alpha)^{2} C_{S}{ }^{-0.8}\right)\left(\frac{H_{O v}}{1-H_{O v}}\right)^{4 / 3}
$$
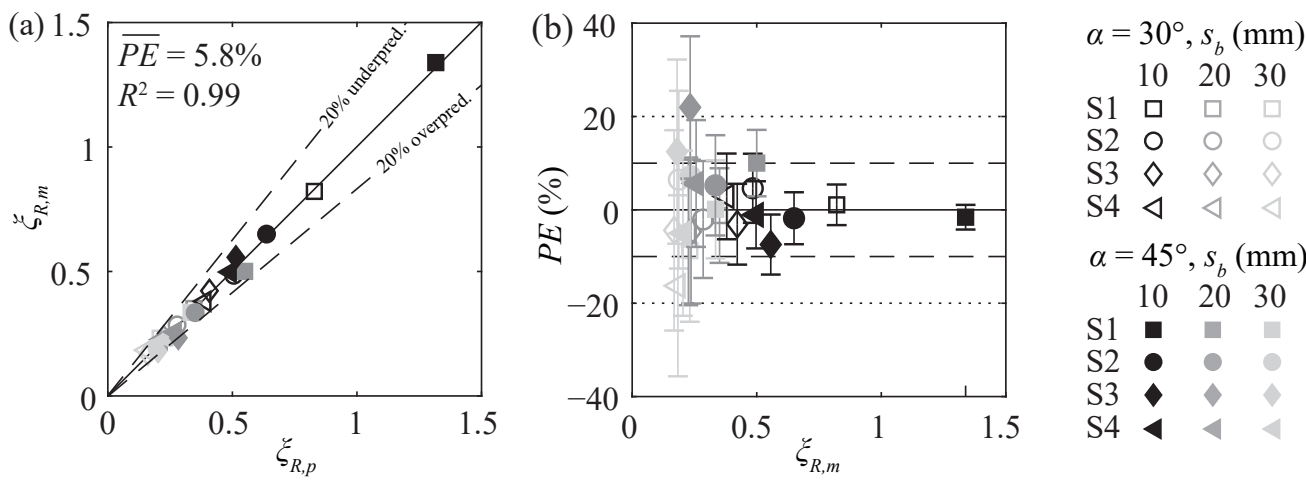

Figure 11. Rack head loss coefficients $\xi_{R}$ for configurations without overlays with (a) comparison of measured $\left(\xi_{R, m}\right)$ and predicted values ( $\xi_{R, p}$; Equation (6) for hydrodynamic bars and Equation (11) for rectangular bars) and (b) prediction error $P E$ as a function of measured rack head loss coefficients $\xi_{R, m}$. $\alpha$ : horizontal approach flow angle, $s_{b}$ : clear bar spacing.

For racks without overlays, $C_{O v}=1.0$. On the basis of the investigated rack configurations with overlays and $\alpha=30^{\circ}$ and $45^{\circ}, \mathrm{C}_{\mathrm{Ov}}$ is minimal for S1, $\alpha=30^{\circ}, s_{b}=10 \mathrm{~mm}(B R \approx 0.49)$, and $H_{O v}=0.1$ $\left(C_{O v}=1.2\right)$. It is maximal for $\mathrm{S} 3 / \mathrm{S} 4, \alpha=45^{\circ}, s_{b}=30 \mathrm{~mm}(B R \approx 0.28)$, and $H_{B o}=H_{T o}=0.2\left(H_{O v}=0.4\right.$; $C_{O v}=7.2$. In other words, overlays increase the head losses by $20 \%-620 \%$, depending on the bar shape and rack configuration.

The predicted $\xi_{R, p}$ values are in good agreement with the experimentally determined loss coefficients $\xi_{R, m}$ using Equation (6) for S2-S4 and Equation (11) for S1 (Figure 12a). For the vast majority of data, $P E$ is within $\pm 20 \%$ for the configurations with combined bottom and top overlays (Figure 12b), bottom overlays only (Figure 12c), and top overlays only (Figure 12d). The outlier in Figure $12 \mathrm{~b}$ with the largest error of $P E \approx 40 \%$ resulted for a worst case combination of rectangular bars (S1) with $\alpha=30^{\circ}$, small bar spacing $s_{b}=10 \mathrm{~mm}$, and a very large overlay blocking $H_{B o}=H_{T o}=0.2$. However, this deviation has little practical relevance, as HBRs with $s_{b}=10 \mathrm{~mm}(B R \approx 0.49)$ and $H_{O v}=$ 0.4 are typically equipped with hydrodynamic bars.

(a)

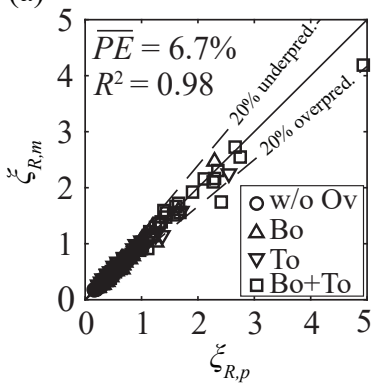

(b)

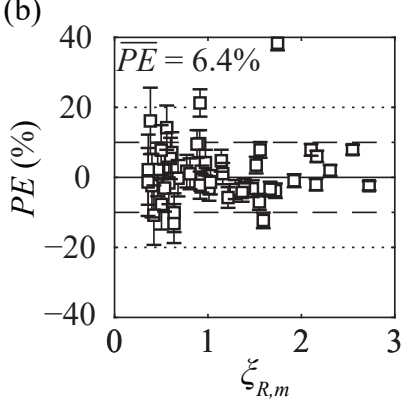

(c)

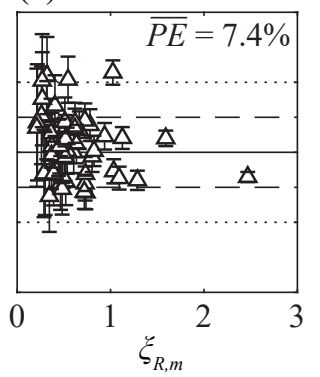

(d)

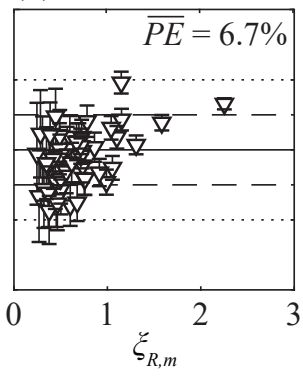

Figure 12. Rack head loss coefficients $\xi_{R}$ for configurations with and without overlays with (a) comparison of measured $\left(\xi_{R, m}\right)$ and predicted values $\left(\xi_{R, p}\right.$; Equation (6) for hydrodynamic bars and Equation (11) for rectangular bars) for all tested configurations, and prediction errors $P E$ as a function of measured rack head loss coefficients $\xi_{R, m}$ for (b) combined bottom and top overlays (Bo + To), (c) bottom overlays only (Bo), and (d) top overlays only (To). w/o Ov: racks without overlays. 


\subsection{Application of Equations to Larger Approach Flow Angles}

The equations presented above are based on measurements for rack configurations with $\alpha=30^{\circ}$ and $\alpha=45^{\circ}$. To verify the applicability of Equations (6) and (11) for $\alpha>45^{\circ}$, validation measurements were conducted with $\alpha=90^{\circ}$ for the rack configuration S2, $s_{b}=20 \mathrm{~mm}(B R=0.35)$, and S1, $s_{b}=10,20$, $30 \mathrm{~mm}(B R=0.483,0.342,0.272)$ for all overlay combinations listed in Section 2.2 (Figure 13). Without overlays, the mean prediction errors are small $\left(\overline{P E}_{\mathrm{S} 1}=8 \%, \overline{P E}_{\mathrm{S} 2}=3 \%\right)$. With overlays, the predicted $\xi_{R, p}$ values also agree well with $\xi_{R, m}$. The individual $P E$ was below $35 \%$ for all configurations, except for S1, $\alpha=90^{\circ}, H_{B o}=H_{T o}=0.2$ with $s_{b}=20 \mathrm{~mm}$ and $s_{b}=30 \mathrm{~mm}(P E=44 \%, P E=64 \%)$. This overprediction of $\xi_{R}$ for rack configurations with rectangular bars (S1), $\alpha=90^{\circ}$, and large overlay blockage is of low importance, because of the low practical relevance of that configuration. The mean prediction error of all rack configurations with $\alpha=90^{\circ}$ is $\overline{P E}_{\mathrm{S} 1}=20.2 \%$ and $\overline{P E}_{\mathrm{S} 2}=14.3 \%$, indicating an application range of $\alpha=30^{\circ}-90^{\circ}$ for the proposed equations.

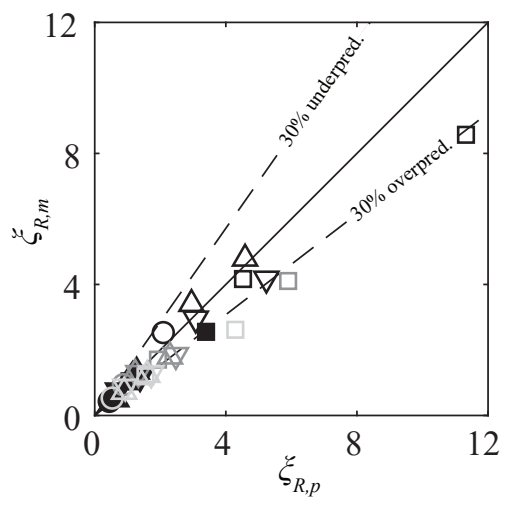

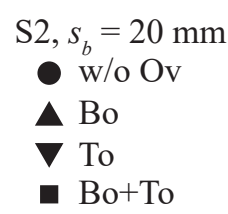

$\mathrm{S} 1, s_{b}=10 \mathrm{~mm}$

$\mathrm{O}$ w/o Ov

$\triangle \mathrm{Bo}$

$\nabla$ To

$\square \mathrm{Bo}+\mathrm{To}$
$\mathrm{S} 1, s_{b}=20 \mathrm{~mm}$
o w/o Ov
$\triangle \mathrm{Bo}$
$\nabla$ To
$\square$ Bo+To

$\mathrm{S} 1, s_{b}=30 \mathrm{~mm}$

w/o Ov

$\triangle$ Bo

$\nabla$ To

$\square \mathrm{Bo}+\mathrm{To}$

Figure 13. Comparison of measured and predicted rack head loss coefficients $\xi_{R, m}$ and $\xi_{R, p}$ (Equation (6) for hydrodynamic bars and Equation (11) for rectangular bars) for rack configurations with S1- and S2-bars and approach flow angle $\alpha=90^{\circ}$. w/o Ov: racks without overlays, Bo: racks with bottom overlays only, To: racks with top overlays only, Bo+To: racks with combined bottom and top overlay.

\subsection{HPP Layouts}

The data presented above corresponded to a straight channel with constant channel width, typically representing diversion HPPs (Figure 3a). At block-type HPPs with turbines and weir adjacent to each other, additional losses are created by flow contractions (Figure 3b). According to Idelchik [26], the resulting contraction head loss coefficient related to $U_{d s}$ is determines with Equation (13) as

$$
\xi_{c, p}=\frac{1}{2}\left(1-\frac{A_{d s}}{A_{o}}\right)^{3 / 4}
$$

where $A_{o}$ is the approach flow cross-sectional area and $A_{d s}$ is the cross-sectional area downstream of the contraction. The predicted losses of a sharp contraction without an HBR installed are in good agreement $(P E \leq 25 \%)$ with the measurements $\left(\xi_{c, p}=0.15,0.22,0.30\right.$ vs. $\xi_{c, m}=0.12,0.20,0.29$ for $w_{o} w_{d s}{ }^{-1}=1.25,1.5$, and 2 , respectively). The head loss coefficients derived from the measurements at the block-type HPP setup with an $\operatorname{HBR}\left(\xi_{(R+c), m}\right)$ were consistently larger than the sum of the predicted rack head losses $\left(\xi_{R, p}\right.$, Equation 6) and the predicted contraction losses ( $\xi_{c, p}$, Equation (13)). The measurements indicate that HBRs at block-type HPPs do not only induce rack head losses, but they also increase the contraction losses by a factor of 1.7. Therefore, with the contraction head loss $\Delta h_{c}=\xi_{c} U_{d s}^{2}(2 g)^{-1}$, Equation (3) is expanded to determine the rack head losses in general form to

$$
\Delta h_{R}=h_{o}+\frac{U_{o}^{2}}{2 g}-h_{d s}-\frac{U_{d s}^{2}}{2 g}-\Delta h_{f}-1.7 \Delta h_{c}
$$


With only one outlier, head losses of HBRs at block-type HPPs can be predicted with Equation (14) with a maximal $P E$ of $\pm 20 \%$ for all investigated contraction ratios (Figure 14a,b). Using Equations (6) and (11) combined with Equation (13) is recommended, not only for block-type HPPs, but also for diversion HPPs with flushing gates or any other hydraulic structures causing flow contractions. The factor of 1.7 will reduce if a dividing pier is installed between the HBR and the spillway. However, using a factor of 1.7 is conservative.
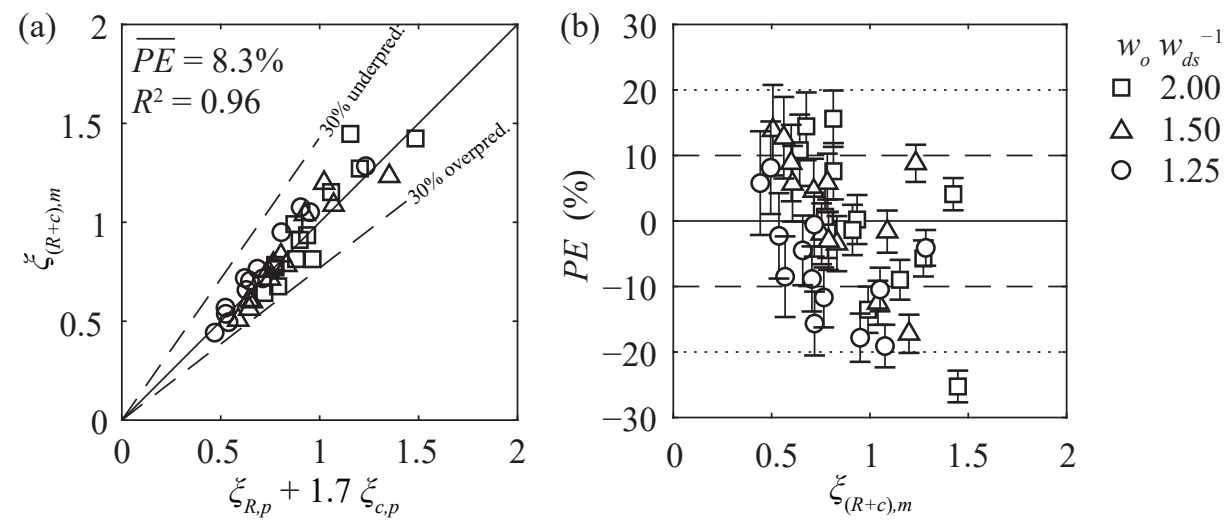

Figure 14. (a) Comparison of predicted and measured head loss coefficients at block-type hydropower plants with horizontal bar racks and (b) corresponding prediction errors $P E . \xi_{(R+c), m}$ : measured rack head loss coefficient at block-type hydropower plants; $\xi_{R, p}$ : predicted head loss coefficient of the horizontal bar rack; $\xi_{c, p}$ : predicted contraction head loss coefficient (Equation (13)); $w_{0}$ : upstream channel width; $w_{d s}$ : downstream channel width.

If an HPP setup differs from a diversion HPP (e.g., block-type setup, side intakes), the streamline pattern is usually complex and the definition of the horizontal approach flow angle is ambiguous. For such situations, the approach flow angle is determined by trigonometry with Equation (15) as

$$
\alpha=\arcsin \left(w_{d s} l_{R}^{-1}\right),
$$

where $l_{R}$ is the rack length.

\section{Discussion}

\subsection{Bar Depth Effect}

Prototype HBRs are built with bars of $t_{b}=5-20 \mathrm{~mm}$ and $d_{b}=40-100 \mathrm{~mm}$, typically leading to relative bar depths of $D_{b}=d_{b} t_{b}{ }^{-1}=5-10$. On the one hand, bars with large $D_{b}$ implicate a large surface area and thus higher friction losses. On the other hand, longer bars may improve the flow straightening effect and therefore reduce losses caused by vortex shedding. The coefficient 0.04 in Equation (10) was determined by a multiple linear regression for bar depths $D_{b}=5.5,7.5,9.5,12$, and 15 , as a linear trend was observed within this range (Figure $8 b$ ). In the present study, the bar depth was investigated for $\alpha=30^{\circ}$ and $\alpha=90^{\circ}$. In addition to $\alpha=30^{\circ}$, a rack angle of $\alpha=45^{\circ}$ was investigated by Maager [20] and Albayrak et al. [21] for $D_{b}=5$ and 10, and $B R=0.55,0.39$, and $0.33\left(s_{b}=10,20\right.$, and $30 \mathrm{~mm}$; prototype dimensions) for rectangular bars with various overlay configurations. On the basis of 38 measurements with S1-bars, $H_{O v} \leq 0.4$ and $\alpha=30^{\circ}$, the rack head loss coefficient $\xi_{R}$ reduced on average by $15 \%$ if the bar depth was halved from $D_{b}=10$ to $D_{b}=5$. For $\alpha=45^{\circ}$, this reduction was only $10 \%$. The bar depth effect observed for $\alpha=45^{\circ}$ therefore reduces to $C_{D b \text {,red }} \approx 10 \% / 15 \% \approx 67 \%$ of the bar depth effect observed for $\alpha=30^{\circ}$ (Figure 15, asterisk symbols). This effect of the rack angle $\alpha$ on the bar depth effect, where $C_{D b}$ is calculated with Equation (10), results in Equation (16).

$$
C_{D b, \text { red }}=\frac{\left(C_{D b} \mid D_{b}, \alpha=45^{\circ}\right)-\left(C_{D b} \mid 0.5 D_{b}, \alpha=45^{\circ}\right)}{\left(C_{D b} \mid D_{b}, \alpha=30^{\circ}\right)-\left(C_{D b} \mid 0.5 D_{b}, \alpha=30^{\circ}\right)} \cdot 100 \%=74 \%
$$




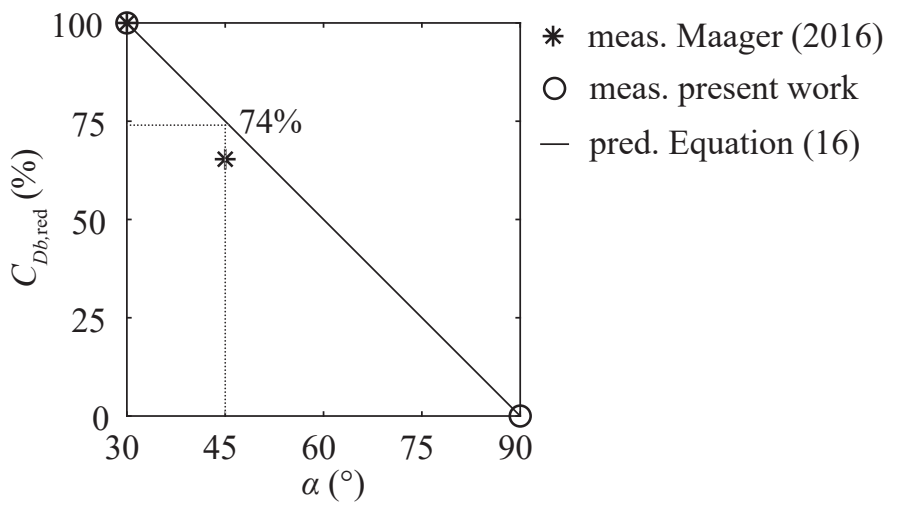

Figure 15. Effect of approach flow angle $\alpha$ on bar depth coefficient $C_{D b}$ for a reduction of relative bar depth $D_{b}$ by $50 \%$.

The measurements of Maager [20], the present work, and the prediction with Equation (16) are shown in Figure 15. The good agreement of $C_{D b \text {,red }}$ for $\alpha=45^{\circ}$ and Equation (16) supports the linear relation between $\alpha$ and $C_{D b}$.

Kirschmer [17] experimentally investigated the effect of the bar depth $\left(D_{b}=2.5,5,10\right)$ on the rack head loss coefficient for traditional trash racks with rectangular vertically oriented bars $\left(\gamma=90^{\circ}, B R=\right.$ 0.37). He found no significant effect of $D_{b}$ on $\xi_{R}$. This can be explained by the small blocking ratios and the perpendicular orientation of the bars to the main flow. In the present work, $D_{b}$ had an effect on $\xi_{R}$ for $\alpha=30^{\circ}$ but not for $\alpha=90^{\circ}$. Similarly, it is possible that the effect of $D_{b}$ on $\xi_{R}$ was not negligible for $\gamma \neq 90$ (Figure 1). However, it is still feasible to apply the equation of Kirschmer [17] for the head loss prediction of traditional trash racks, as $\gamma$ is typically close to $\gamma=90^{\circ}$, that is, in the range of $\gamma=$ $70^{\circ}-80^{\circ}$ [19]. However, if the equation of Kirschmer [17] is applied for racks with small $\alpha$ or $\gamma, \xi_{R}$ would be expected to be overpredicted for short bars $\left(D_{b}<<5\right)$ and underpredicted for deep bars $\left(D_{b}>>5\right)$. Although the effect of $D_{b}$ on $\xi_{R}$ was investigated for S2-bars only, due to the similar head loss behavior of S2-S4 bars, it is assumed that the trend can be transferred to all hydrodynamic bar shapes. The measurements of [20] and [21] further indicate that Equation (10) can also be used for rectangular bars. Therefore, $C_{D b}$ is also included in Equation (11). The measurements in Figure $8 \mathrm{~b}$ show that the effect of $D_{b}$ on $\xi_{R}$ is most pronounced for $s_{b}=10 \mathrm{~mm}(B R \approx 0.49)$. However, the bar depth effect was similar for $s_{b}=20 \mathrm{~mm}(B R \approx 0.35)$ and $s_{b}=30 \mathrm{~mm}(B R \approx 0.28)$, which is supported by other studies [20,21]. Therefore, the effect of $s_{b}$ on $C_{D b}$ is neglected in Equation (10). For practical application at a typical HBR with $\alpha=30^{\circ}$ and $D_{b}=5-10$, the effect of $D_{b}$ on $\xi_{R}$ is small $( \pm 10 \%)$. However, if the bars are very short $\left(D_{b}=3.5\right)$ or very deep $\left(D_{b}=15\right), \xi_{R}$ can reduce by $16 \%$ or increase by $30 \%$, respectively, in comparison to $D_{b}=7.5$.

\subsection{Effect of Vertical Tie-Bars}

Prototype HBRs are usually assembled using a number of vertical tie-bars installed with a horizontal spacing of $0.4-0.8 \mathrm{~m}$, whereas for the model rack two tie-bars $(Y=0.25,0.75$; Section 2.1) with a spacing of $0.25,0.35$, and $0.50 \mathrm{~m}$ were used for $\alpha=90^{\circ}, 45^{\circ}$, and $30^{\circ}$, respectively. These tie-bars can be of different shapes, such as cylindrical or rectangular. Given identical dimensions, cylindrical obstacles generate smaller head losses as compared to rectangular objects with sharp edges. For rectangular objects, an oblique approach flow further increases the flow separation and thus head losses. To minimize losses and the effect on the flow field, rectangular tie-bars should be aligned with the main flow direction. Within the present work, the head losses of the used mounting parts (cylindrical vertical tie-bars and bottom plate) were individually measured without horizontal bars installed. For rack configurations with large $\xi_{R}\left(\mathrm{~S} 1, \alpha=45^{\circ}, s_{b}=10 \mathrm{~mm}\right)$ these mounting parts accounted for only $3 \%$ of the overall losses. However, for a hydrodynamically optimized rack configuration (S4, $\alpha=30^{\circ}$, $s_{b}=$ $30 \mathrm{~mm}$ ) with small overall losses, they accounted for up to $25 \%$ of $\xi_{R}$. The effect of the mounting parts is included in Equations (6) and (11) by calculating the BR of racks with cylindrical tie-bars. 


\subsection{Comparison of Head Loss Prediction Equations with Literature Data}

Many different layouts of fish guidance structures are described in the literature, but only sparse data are available on the head losses of angled HBRs as investigated in the present study. In the studies of Maager [20] and Albayrak et al. [21], the head losses of HBRs were measured for overlays with $H_{O v}$ up to 0.5 , creating a large flow diversion and corresponding loss coefficients up to $\xi_{R, m}=28$. Herein, only the head loss measurements of rack configurations with $H_{B o} \leq 0.2$ and $H_{T o} \leq 0.2$ were used to validate (subscript val) the proposed equations of the present investigation. Figure 16a compares the head loss coefficients of racks with rectangular bars measured by Maager [20] $\xi_{R, m, v a l}$ with the corresponding $\xi_{R, p}$ values predicted using Equation (11). The majority of data points were predicted with an accuracy of $\pm 30 \%$ with $\overline{P E}=13.3 \%$ (Figure 16a). If the proposed equation for hydrodynamic bars (Equation (6)) was used for the one-side rounded bars of Maager (2016) [20], significant deviations result, indicating that the hydraulic processes at the latter were more similar to rectangular bars. A good agreement $(\overline{P E}=11.7 \%)$ was found for the one-side rounded bars if the proposed equation for rectangular bars (Equation (11)) was used with a prefactor reduction from 2.33 to 1.60 (Figure 16b). This means that the predicted hydraulic losses of one-side rounded bars were $31 \%$ smaller than the hydraulic losses of rectangular bars. The loss reduction implicated by the shape factors of Kirschmer [17] is 24\%.
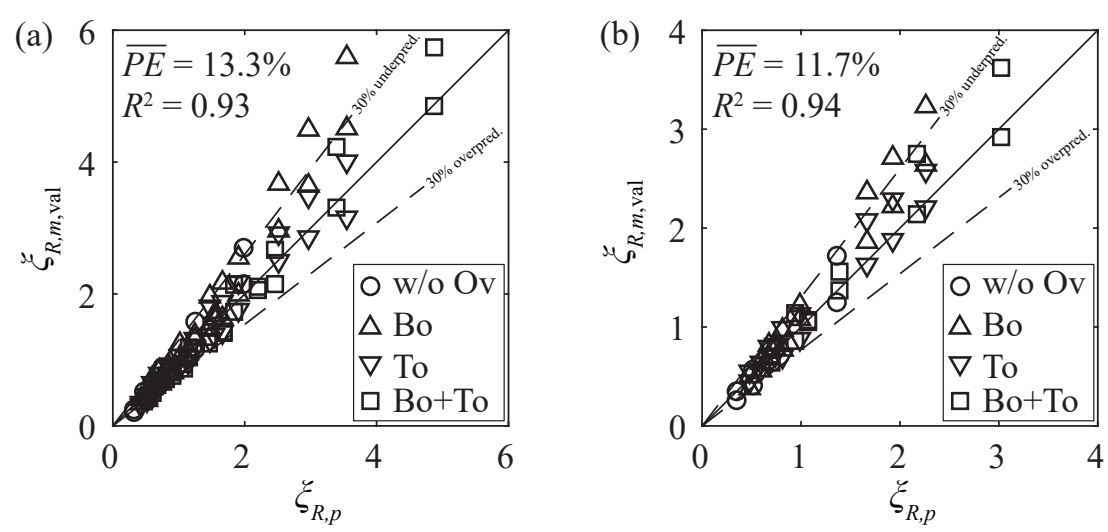

Figure 16. Validation of predicted rack head loss coefficients $\xi_{R, p}$, on the basis of Equation (11), with rack head loss coefficients measured by Maager [20] $\xi_{R, m, \text { val }}$ for (a) rectangular bars and (b) one-side rounded bars (with prefactor of 1.60 instead of 2.33 in Equation (11)). w/o Ov: racks without overlays, Bo: racks with bottom overlays only, To: racks with top overlays only, Bo + To: racks with combined bottom and top overlay.

Böttcher et al. [22] investigated HBRs with cylindrical bars without overlays. Their data can be well predicted with Equation (11) if the prefactor is reduced from 2.33 to 1.72 according to the ratio of the shape factors of cylindrical (1.79) and rectangular bars (2.42) given by Kirschmer [17] (i.e., $2.33 \cdot 1.79 / 2.42=1.72$ ). $P E \leq 30 \%$ for all $\alpha$ and $B R$ (Figure 17), indicating that the proposed equations can be applied for various bar shapes. It is recommended that Equation (6) is used for hydrodynamic bars and Equation (11) for non-hydrodynamic bars such as rectangular bars, one-side rounded bars, and cylindrical bars. 


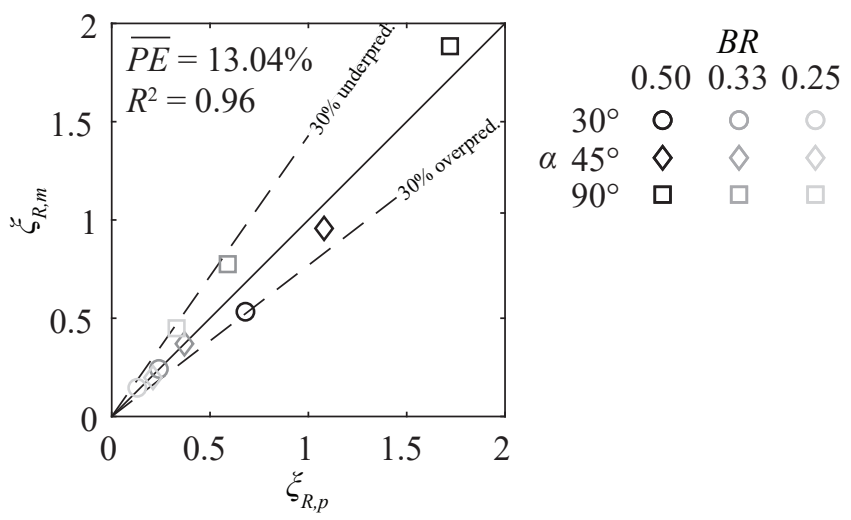

Figure 17. Comparison of rack head loss coefficients $\xi_{R, m}$ measured by Böttcher et al. [22] with predicted rack head loss coefficients $\xi_{R, p}$ for cylindrical bars (Equation (11), adapted). BR: blocking ratio, $\alpha$ : horizontal approach flow angle.

\subsection{Engineering Application}

The predicted head loss coefficient of a typical modern diversion HPP with an HBR with $\alpha=$ $30^{\circ}, s_{b}=20 \mathrm{~mm}(B R \approx 0.35), t_{b}=8 \mathrm{~mm}, D_{b}=7.5$, and S4-bars without overlays is as low as $\xi_{R}=0.22$ (Equation (6)), assuming no blockage by floating debris. For $U_{o}=0.8 \mathrm{~m} \mathrm{~s}^{-1}$, this results in head losses of $\Delta h_{R}=7 \mathrm{~mm}$. The predicted head loss increases by a factor of 4.5 if bottom and top overlays of $H_{B o}=$ $H_{T o}=0.2$ are installed $\left(\xi_{R}=0.98, \Delta h_{R}=32 \mathrm{~mm}\right)$. For rectangular bars (S1), the head losses increase by $\approx 70 \%\left(\xi_{R}=0.37\right.$ and $\left.\Delta h_{R}=12 \mathrm{~mm}\right)$ without overlays, and by $\approx 50 \%\left(\xi_{R}=1.47\right.$ and $\left.\Delta h_{R}=48 \mathrm{~mm}\right)$ with overlays, relative to the $\mathrm{S} 4$ configuration (Equation (11)). For the S1-bars, the overlays thus result in an increase of $\xi_{R}$ by a factor of 4 . If constructional considerations are not limiting (e.g., mounting of tie-bars), bars with a relative depth of $D_{b}=5.5$ are recommended to reduce costs and hydraulic losses. For practical applications, the effect of $D_{b}$ on $\xi_{R}$ can be larger than described in Section 4.1 if algae growth increases the surface roughness.

Meusburger [19] analyzed the operational data of 43 Swiss run-of-river HPPs with $Q_{d} \geq 25 \mathrm{~m}^{3} \mathrm{~s}^{-1}$. The head loss coefficients with respect to $U_{t h}$ of traditional trash racks were $\xi_{R}=0.10-5.04$ with an average of 1.67 and a standard deviation of $\sigma=1.20$. The head losses of clean, unclogged HBRs are therefore of comparable order. No pronounced increase of head losses is expected if these traditional trash racks were replaced by HBRs, provided that substantial clogging can be prevented by an automated rack cleaning machine. Meusburger [19] also showed that the head losses of traditional trash racks at existing HPPs are significantly higher than predicted by the equation proposed by Kirschmer [17], who conducted his measurements in a straight laboratory flume representing diversion HPPs. However, his empirical equation is often applied to block-type HPPs without considering the oblique approach flow and the effect of increased contraction losses due to the rack, as described in Section 3.4. It is important to consider not only the rack itself, but also the HPP layout when head losses are estimated for engineering applications. The higher losses might also be caused by partial clogging of racks at prototype HPPs, which was not considered by Kirschmer [17]. During high flows or even flood events in autumn, some HPP operators report head losses at HBRs caused by foliage clogging of up to $\Delta h_{R}=30 \mathrm{~cm}$, requiring HPP shutdowns as a safety measure. In addition, Kirschmer's [17] equation does not include the effects of further support bars or intermediate piers, which are typically needed for large flow depths to distribute the substantial additional load in case of rack clogging. When the equations of the present work are used for practical applications, further support bars can be considered with an increased $B R$. Potential foliage clogging can be accounted for by substituting the clogged areas with overlays (Equation (12)). If no site-specific information is available, Turnpenny and O'Keeffe [4] suggest assuming that at least $20 \%$ of the rack area gets clogged. 


\subsection{Fish Protection}

The findings presented above do not justify statements or predictions on the individual fish behavior at HBRs or their overall fish protection suitability at HPPs. A rack configuration, which is favorable with respect to head losses, is not necessarily favorable for fish protection. As an example, HBRs with foil-shaped bars induce smaller head losses than HBRs with rectangular bars due to the smaller flow separation zones between the bars. Assuming avoidance reactions of fish to these flow separation zones, rectangular bars might be beneficial for fish protection. The goal of the present study was limited to describing the head losses generated by HBRs, and to propose head loss equations, covering a wide parameter range and different HPP layouts. The selected parameter range covers the typical application range of HBRs (e.g., $\alpha=30^{\circ}$ and $45^{\circ}$ ), but it also includes measurements for untypical HBR configurations to validate the proposed equations. For instance, HBR configurations with $\alpha=90^{\circ}$ are unsuitable for fish protection because of the missing guidance effect due to the missing sweeping flow component parallel to the rack to guide fish towards the bypass. For such large $\alpha$, the velocity component normal to the rack $V_{n}$ is often larger than the sustained fish swimming speed, increasing the risk of fish impingements [1,4]. Top and bottom overlays are part of an HBR design, which can significantly increase head losses. Despite this, laboratory studies indicate higher guidance for bottom- and surface-oriented fish [9,27]. Additionally, overlays improve the routing of driftwood and sediments towards the bypass [1]. Overall, the selection of geometric parameters for an optimum HBR design with regard to high fish guidance and protection depends not only on head loss but also on the resulting velocity field, which influences the fish behavior. Therefore, velocity fields of a range of HBR configurations for different HPP layouts are published in the accompanying paper [25]. They can be used to estimate the fish behavior at fish guidance structures during the planning phase. Feigenwinter et al. [28] present a conceptual approach for the evaluation of potential locations of fish guidance structures combining traditional design principles with computational fluid dynamics and novel findings from ethohydraulic research. The approach is based on the three key aspects fish fauna, structural conditions, and hydraulic conditions such as velocity fields and head losses. Nevertheless, to reliably assess the fish behavior at HBRs, live fish tests or extensive field monitoring campaigns at HPPs equipped with HBRs are indispensable.

\section{Conclusions}

In the present study, the head losses of horizontal bar racks were investigated in a sectional laboratory model of Froude scale 1:1. Potential model effects were studied to ensure the transferability of the results to prototype situations. The parameter variation included different bar shapes (rectangular and three types of hydrodynamic bars); clear bar spacings $s_{b}=10,20$, and $30 \mathrm{~mm}$; approach flow angles $\alpha=30^{\circ}, 45^{\circ}$, and $90^{\circ}$; relative bar depths $D_{b}=d_{b} t_{b}{ }^{-1}=3.5-15$; and a wide range of overlay configurations. Additional experiments were conducted for a wider upstream channel to account for different hydropower plant layouts (diversion vs. block-type). The head losses of horizontal bar racks can be predicted using Equations (6) and (11) for hydrodynamic and rectangular bars, respectively, thereby incorporating the following key findings:

(I) The hydraulic processes at racks with rectangular bars differed significantly from hydrodynamic bars. Therefore, separate head loss prediction equations were proposed.

(II) Head losses were significantly reduced by foil-shaped bars. On average, foil-shaped bars led to more than $40 \%$ smaller losses compared with rectangular bars. This loss reduction was more pronounced for racks with large blocking ratios $B R$, large approach flow angles $\alpha$, and small relative overlay blocking ratios $H_{O v}$.

(III) For practical applications at an HBR with an approach flow angle $\alpha=30^{\circ}$ and a relative bar depth of $D_{b}=5-10$, the effect of $D_{b}$ on $\xi_{R}$ is small $(\leq \pm 10 \%)$. However, if very short $\left(D_{b}=3.5\right)$ or very deep bars $\left(D_{b}=15\right)$ are used in combination with small clear bar spacing $\left(s_{b}=10 \mathrm{~mm}\right.$, blocking ratio $B R \approx 0.49), \xi_{R}$ can reduce by $16 \%$ or increase by $30 \%$, respectively, in comparison to $D_{b}=7.5$. 
(IV) Overlays strongly increased head losses. For typical hydropower plants (approach flow angle $\alpha$ $=30^{\circ}$, clear bar spacing $s_{b}=20 \mathrm{~mm}$, blocking ratio $B R \approx 0.35$ ), the application of bottom and top overlays with a height of $20 \%$ of the flow depth $\left(H_{B o}=H_{T o}=0.2\right)$ increased the loss coefficient $\xi_{R}$ by a factor of 4.0-4.5.

(V) The validation showed that the measured head losses of horizontal bar racks with rectangular and cylindrical bars found in the literature can be predicted by Equation (11) with an accuracy of $\pm 30 \%$. A comparable accuracy was reached for one-side rounded and cylindrical bars with Equation (11) if the shape factor was reduced from 2.33 to 1.60 and 1.72, respectively.

(VI) In addition to diversion hydropower plants, the proposed equations can also be applied for block-type hydropower plants. Horizontal bar racks installed at block-type hydropower plants with a sharp contraction increased the contraction losses by a factor of 1.7 .

Author Contributions: Conceptualization, J.M., H.F., and R.M.B.; methodology, J.M. and H.F.; software, J.M.; validation, J.M. and C.B.; formal analysis, J.M.; investigation, J.M.; resources, J.M.; data curation, J.M.; writing—original draft preparation, J.M.; writing—review and editing, J.M., H.F., C.B., I.A., and R.M.B.; visualization, J.M.; supervision, H.F. and R.M.B.; project administration, J.M., H.F., I.A., and R.M.B.; funding acquisition, I.A. and R.M.B. All authors have read and agreed to the published version of the manuscript.

Funding: This project received funding from the European Union's Horizon 2020 research and innovation program under grant agreement no. 727830, FITHydro (Fishfriendly Innovative Technologies for Hydropower). The authors would further like to thank the Swiss State Secretariat for Education, Research and Innovation (SERI) for their support.

Acknowledgments: The authors thank Michael Ruf and Timon Suter who conducted a part of the measurements presented above within their MSc theses. The hydropower research of the Laboratory of Hydraulics, Hydrology and Glaciology of ETH Zurich (VAW) is embedded in the Swiss Competence Center for Energy Research, Supply of Electricity (SCCER-SoE), which is an initiative funded by the Swiss Confederation through Innosuisse (Swiss Innovation Agency).

Conflicts of Interest: The authors declare no conflict of interest.

\section{Abbreviations}

HBR Horizontal bar rack

HPP Hydropower plant

Notation

$A_{d s}=$ cross-sectional area downstream of the rack $\left(\mathrm{m}^{2}\right), A_{d s}=h_{d s} w_{d s}$

$A_{o}=$ approach flow cross-sectional area $\left(\mathrm{m}^{2}\right), A_{o}=h_{o} w_{o}$

$B R=$ total blocking ratio $(-)$

$B R^{*}=$ approximate blocking ratio $(-)$

$B R_{b}=$ blocking ratio of the horizontal bars (-)

$B R_{b p}=$ blocking ratio of the bottom plate (-)

$B R_{S}=$ blocking ratio of the spacers (-)

$C_{B R}=$ blocking ratio coefficient $(-)$

$C_{D b}=$ bar depth coefficient (-)

$C_{D b \text {,red }}=$ reduction of $C_{D b}(\%)$

$\mathrm{C}_{\mathrm{OL}}=$ overlay layout coefficient $(-)$

$\mathrm{C}_{\mathrm{Ov}}=$ overlay coefficient $(-)$

$C_{S}=$ bar shape coefficient $(-)$

$C_{\alpha}=$ approach flow angle coefficient (-)

$d_{b}=$ bar depth $(\mathrm{m})$

$D_{b}=$ relative bar depth $(-), D_{b}=d_{b} t_{b}{ }^{-1}$

$\mathrm{F}=$ Froude number $(-), \mathrm{F}=U_{0} g^{-0.5} h_{o}{ }^{-0.5}$

$g=$ gravity acceleration constant $\left(\mathrm{m} \mathrm{s}^{-2}\right), g=9.81 \mathrm{~m} \mathrm{~s}^{-2}$

$h_{B o}=$ bottom overlay height $(\mathrm{m})$ 
$H_{B o}=$ relative bottom overlay height $(-), H_{B o}=h_{B o} h_{o}{ }^{-1}$

$h_{d s}=$ downstream flow depth (m)

$h_{T o}=$ top overlay height $(\mathrm{m})$

$H_{T o}=$ relative top overlay height $(-), H_{T o}=h_{T o} h_{o}{ }^{-1}$

$h_{0}=$ approach flow depth $(\mathrm{m})$

$H_{O v}=$ total relative overlay height (-), $H_{O v}=H_{B o}+H_{T o}$

$l_{c h}=$ channel length $(\mathrm{m})$

$l_{R}=\operatorname{rack}$ length $(\mathrm{m}), l_{R}=w_{d s} \sin (\alpha)^{-1}$

$n=$ number of data points $(-)$

$n_{b}=$ number of horizontal bars $(-)$

$n_{s}=$ number of spacers per vertical tie-bar (-)

$n_{v}=$ number of vertical tie-bars (-)

$P E=$ prediction error $(\%)$

$\overline{P E}=$ mean prediction error $(\%)$

$Q_{d}=$ design discharge $\left(\mathrm{m}^{3} \mathrm{~s}^{-1}\right)$

$Q_{t}=$ turbine discharge $\left(\mathrm{m}^{3} \mathrm{~s}^{-1}\right)$

$\mathrm{R}=$ Reynolds number based on hydraulic radius $(-), \mathrm{R}=4 R_{h} U_{o} v^{-1}$

$\mathrm{R}_{b}=$ bar Reynolds number $(-), \mathrm{R}_{b}=t_{b} U_{o} v^{-1}$

$R_{h}=$ hydraulic radius $(\mathrm{m}), R_{h}=h w_{c h}\left(2 h+w_{c h}\right)^{-1}$

$s_{b}=$ clear bar spacing $(\mathrm{m})$

$t_{b}=$ bar thickness at thickest point $(\mathrm{m})$

$t_{b, m}=$ bar thickness at mid cross section (m)

$t_{b p}=$ thickness of the bottom plate $(\mathrm{m})$

$U_{d s}=$ mean downstream flow velocity $\left(\mathrm{m} \mathrm{s}^{-1}\right)$

$U_{t h}=$ theoretical average flow velocity $\left(\mathrm{m} \mathrm{s}^{-1}\right)$

$U_{o}=$ mean upstream approach flow velocity from continuity $\left(\mathrm{m} \mathrm{s}^{-1}\right)$

$V_{n}=$ flow velocity component normal to the rack $\left(\mathrm{m} \mathrm{s}^{-1}\right)$

$w_{c h}=$ constant channel width (diversion HPP) (m)

$w_{d s}=$ downstream channel width $(\mathrm{m})$

$w_{0}=$ upstream channel width $(\mathrm{m})$

$x, y, z=$ coordinates in streamwise, transversal, and vertical direction (m)

$X=$ normalized streamwise coordinate $(-), X=x h_{0}{ }^{-1}$

$Y=$ normalized transversal coordinate $(-), Y=y w_{d s}{ }^{-1}$

$\alpha=$ horizontal approach flow angle $\left(^{\circ}\right)$

$\gamma=$ rack inclination angle $\left(^{\circ}\right)$

$\Delta h_{c}=$ contraction head loss $(\mathrm{m})$

$\Delta h_{f}=$ friction head loss (m)

$\Delta h_{R}=$ rack head loss $(\mathrm{m})$

$v=$ kinematic viscosity $\left(\mathrm{m}^{2} \mathrm{~s}^{-1}\right)$

$\xi_{c}=$ contraction head loss coefficient (-)

$\xi_{R}=$ rack head loss coefficient (-)

$\sigma=$ standard deviation

\section{References}

1. Ebel, G. Fischschutz und Fischabstieg an Wasserkraftanlagen-Handbuch Rechen- und Bypasssysteme. Ingenieurbiologische Grundlagen, Modellierung und Prognose, Bemessung und Gestaltung (Fish Protection and Downstream Passage at Hydro Power Stations-Handbook of Bar Rack and Bypass Systems. Bioengineering Principles, Modelling and Prediction, Dimensioning and Design), 2nd ed.; Büro für Gewässerökologie und Fischereibiologie Dr. Ebel: Halle (Saale), Germany, 2016. (In German)

2. Gruber, R. Traun-Kraftwerk Danzermühl nimmt planmässig den Betrieb auf (The hydropower plant Danzermühl at Traun River starts operation on schedule). zekHydro 2019, 17, 22-27. (In German)

3. Larinier, M.; Travade, F. Downstream migration: Problems and facilities. Bull. Fr. Pêche Piscic. 2002, 364, 181-202. [CrossRef] 
4. Turnpenny, A.W.H.; O'Keeffe, N. Screening for Intake and Outfalls: A Best Practice Guide; SC030231; Environment Agency: Bristol, UK, 2005.

5. USBR. Fish Protection at Water Diversions-A Guide for Planning and Designing Fish Exclusion Facilities; U.S. Department of the Interior, Bureau of Reclamation: Denver, CO, USA, 2006.

6. Kriewitz, C.R. Leitrechen an Fischabstiegsanlagen: Hydraulik und fischbiologische Effizienz (Guidance screens at fish protection facilities-Hydraulics and fish-biological efficiency). In VAW-Mitteilungen 230; Boes, R.M., Ed.; Laboratory of Hydraulics, Hydrology and Glaciology (VAW), ETH Zurich: Zurich, Switzerland, 2015. (In German)

7. Bates, D.W.; Vinsonhaler, R. Use of louvers for guiding fish. Trans. Am. Fish. Soc. 1957, 86, 38-57. [CrossRef]

8. Ducharme, L.J.A. An application of louver deflectors for guiding atlantic salmon (Salmo salar) smolts from power turbines. J. Fish. Res. Board Can. 1972, 29, 1397-1404. [CrossRef]

9. EPRI; DML. Evaluation of Angled Bar Racks and Louvers for Guiding Fish at Water Intakes; 1005193; Electric Power Research Institute (EPRI) and Dominion Millstone Laboratories (DML): Palo Alto, CA, USA; Waterford, CT, USA, 2001.

10. Boes, R.M.; Albayrak, I.; Kriewitz, C.R.; Peter, A. Fischschutz und Fischabstieg mittels vertikaler Leitrechen-Bypass-Systeme: Rechenverluste und Leiteffizienz (Fish protection and downstream fish migration by means of guidance systems with vertical bars: Head loss and bypass efficiency). Wasserwirtschaft 2016, 106, 29-35. (In German) [CrossRef]

11. Albayrak, I.; Kriewitz, C.R.; Hager, W.H.; Boes, R.M. An experimental investigation on louvres and angled bar racks. J. Hydraul. Res. 2018, 56, 59-75. [CrossRef]

12. Beck, C.; Albayrak, I.; Meister, J.; Boes, R.M. Hydraulic performance of fish guidance structures with curved bars-Part 1: Head loss assessment. J. Hydraul. Res. 2019. [CrossRef]

13. Beck, C.; Albayrak, I.; Meister, J.; Boes, R.M. Hydraulic performance of fish guidance structures with curved bars-Part 2: Flow fields. J. Hydraul. Res. 2019. [CrossRef]

14. Dumont, U.; Anderer, P.; Schwevers, U. Handbuch Querbauwerke (Handbook transverse structures); Ministerium für Umwelt und Naturschutz, Landwirtschaft und Verbraucherschutz des Landes Nordrhein-Westfalen: Düsseldorf, Germany, 2005. (In German)

15. Raynal, S.; Courret, D.; Chatellier, L.; Larinier, M.; David, L. An experimental study on fish-friendly trashracks-Part 1. Inclined trashracks. J. Hydraul. Res. 2013, 51, 56-66. [CrossRef]

16. Larinier, M. Fish passage experience at small-scale hydro-electric power plants in France. Hydrobiol. 2008, 609, 97-108. [CrossRef]

17. Kirschmer, O. Untersuchungen über den Gefällsverlust an Rechen (Investigation of Head Losses at Racks). Ph.D. Thesis, Technical University of Munich, Munich, Germany, 1925. (In German).

18. Zimmermann, J. Widerstand schräg angeströmter Rechengitter (Resistance of racks caused by oblique inflow). In Mitteilung Nr. 157; Mosonyi, E., Ed.; Theodor-Rehbock-Flußbaulaboratorium, Universität Fridericiana Karlsruhe: Karlsruhe, Germany, 1969; pp. 1-130. (In German)

19. Meusburger, H. Energieverluste an Einlaufrechen von Flusskraftwerken (Hydraulic losses at bar racks of run-of-river plants). In VAW-Mitteilung 179; Minor, H.E., Ed.; Laboratory of Hydraulics, Hydrology and Glaciology (VAW), ETH Zurich: Zurich, Switzerland, 2002. (In German)

20. Maager, F. Fischleitrechen mit horizontalen Stabelementen (Fish Guidance Structures with Horizontal Bars). Master's Thesis, ETH Zurich, Zurich, Switzerland, 2016. (In German).

21. Albayrak, I.; Maager, F.; Boes, R.M. An experimental investigation on fish guidance structures with horizontal bars. J. Hydraul. Res. 2019, 1-15. [CrossRef]

22. Böttcher, H.; Gabl, R.; Aufleger, M. Experimental hydraulic investigation of angled fish protection systems-comparison of circular bars and cables. Water 2019, 11, 1056. [CrossRef]

23. Berger, C. Rechenverluste und Auslegung von (elektrifizierten) Schrägrechen anhand ethohydraulischer Studien (Screen Losses and Design of Inclined (and Electrified) Screens with Horizontal Bars on the Basis of Ethohydraulic Studies). Ph.D. Thesis, Technische Universität Darmstadt, Darmstadt, Germany, 2018. (In German).

24. Szabo-Meszaros, M.; Navaratnam, C.U.; Aberle, J.; Silva, A.T.; Forseth, T.; Calles, O.; Fjeldstad, H.-P.; Alfredsen, K. Experimental hydraulics on fish-friendly trash-racks: an ecological approach. Ecol. Eng. 2018, 113, 11-20. [CrossRef] 
25. Meister, J.; Fuchs, H.; Beck, C.; Albayrak, I.; Boes, R.M. Velocity fields at horizontal bar racks as fish guidance structures. Water 2020, 12, 280. [CrossRef]

26. Idelchik, I.E. Handbook of Hydraulic Resistance, 3rd ed.; Jaico Publishing House: Mumbai, India, 2008.

27. Albayrak, I.; Boes, R.M.; Kriewitz, C.R.; Peter, A.; Tullis, B.P. Fish guidance structures: Hydraulic performance and fish guidance efficiencies. J. Ecohydraul. 2019, 1-19. [CrossRef]

28. Feigenwinter, L.; Vetsch, D.F.; Kammerer, S.; Kriewitz, C.R.; Boes, R.M. Conceptual approach for positioning of fish guidance structures using CFD and expert knowledge. Sustainability 2019, 11, 1646. [CrossRef]

(C) 2020 by the authors. Licensee MDPI, Basel, Switzerland. This article is an open access article distributed under the terms and conditions of the Creative Commons Attribution (CC BY) license (http://creativecommons.org/licenses/by/4.0/). 